\title{
TRES PARA DOS. LAS FORMAS DE POBLAMIENTO EN LA EDAD DEL HIERRO DEL NOROESTE IBÉRICO
}

\author{
THREE FOR TWO. THE FORMS OF SETTLEMENT IN NORTH WESTERN IBERIAN \\ IRON AGE
}

CÉSAR PARCERO OUBIÑA $(*)$

\begin{abstract}
RESUMEN
Se realiza un detallado análisis locacional de los poblados castreños de un área de Galicia según una propuesta metodológica apoyada en el empleo de Sistemas de Información Geográfica. Con ello se distinguen dos modelos de situación de los yacimientos, que se corresponden con diferencias en los rasgos formales de los propios castros. Esto permite establecer una secuencia de 'desarrollo cultural' alternativa a las tres fases tradicionales, articulada en una Primera Edad del Hierro bien diferenciada de la aparente continuidad entre la Segunda Edad del Hierro y la época de ocupación romana. Para terminar, tomando como eje argumental datos del yacimiento de Alto do Castro, se discute la opción alternativa de la larga continuidad en la ocupación de un mismo punto y se muestra que no es contradictoria con la secuencia histórica propuesta. Esto permite además valorar la representatividad de los resultados obtenidos en el área elegida.
\end{abstract}

\begin{abstract}
A detailed locational analysis of Iron Age hillforts in an area of Galicia is performed, using a methodology based on the use of Geographic Information Systems. Two models of location are revealed from this analysis, corresponding to differences in the formal appearance of hillforts. That allows us to suggest a sequence of 'cultural development' rather than the three traditional phases. This is structured in an Early Iron Age, which is fairly different from the apparent continuity between the Second Iron Age and the indi-
\end{abstract}

(*) Laboratorio de Arqueoloxía e Formas Culturais. Instituto de Investigacións Tecnolóxicas. Edificio Monte da Condesa. Campus Sur - USC. 15706 Santiago de Compostela. Correo electrónico: phcpar@usc.es

El artículo fue remitido en su versión final el 17-I-2000.
genous-Roman period. Finally the alternative option of the long term occupation is discussed, based on the data from the site of Alto do Castro and its coherence with the proposed historical sequence is shown. This also allows us to evaluate the significance of the results obtained in the selected area.

Palabras clave: Arqueología del Paisaje. Primera Edad del Hierro. Segunda Edad del Hierro. Castros. Galicia. Modelos de ocupación. SIG.

Key words: Landscape Archaeology. Early Iron Age. Late Iron Age. Hillforts. Galicia. Settlement patterns. GIS.

\section{PRESENTACIÓN E INTENCIONES}

Hace unos años publicaba un artículo que sugería algunos elementos para la comprensión del poblamiento castreño en el noroeste de la Península Ibérica (Parcero, 1995). Aquella primera visión era, ante todo, muy general y, como se ha apuntado con acierto, teórica y en cierto modo atemporal (Fernández-Posse y Sánchez Palencia, 1998). Un tiempo después me gustaría hacer algunas contribuciones nuevas a lo que, en fechas recientes, está siendo un importante proceso de revisión e impulso de este tema de estudio.

Uno de los primeros asuntos que pretendo abordar es su pretendida especificidad y originalidad con respecto a cualquier otra forma socio-cultural. Esta característica singular de la historiografía arqueológica de este período y área se manifiesta en la defensa de formas de organización socio-política castreña únicas e irrepetidas o en el manejo de secuencias evolutivas igualmente peculiares que 
impiden -al menos dificultan-cualquier intento de trascender los límites del noroeste y poder intercambiar experiencias y puntos de vista con otros contextos (Fernández-Posse, 1998).

También se ha señalado en fechas recientes que uno de los temas favoritos de la investigación protohistórica en el noroeste ha sido la periodización, hasta el punto de que casi no hay arqueólogo sin la suya propia (Fernández-Posse, 1998). Sin embargo la gran mayoría de ellas tienen una base y finalidad exclusivamente cronológica y se apoyan casi únicamente en la evolución formal de la cultura material, cuando no directamente en la presencia/ausencia de indicadores materiales exógenos, de alta cultura. Si nuestro interés es comprender el mundo castreño, la finalidad de una secuencia ha de ser reconocer situaciones y contextos socio-políticoculturales, estructuras, y analizar los procesos de cambio y sustitución de unas por otras. El tiempo métrico, la cronología, habrá de ser tan sólo un rasgo adjetivo.

Un tercer asunto es la relación entre espacio y tiempo, dimensiones que, cuando menos para este contexto investigador, casi siempre han sido tratadas de forma independiente. Existen abundantes ejemplos de estudios con perspectiva temporal, así como otra buena cantidad de análisis de contenido espacial (Carballo, 1990; Xusto, 1992; Parcero, 1995), a los que se suele achacar, precisamente, su falta de concreción temporal (Fernández-Posse y Sánchez Palencia, 1998: 129). La conjunción de ambas perspectivas es ciertamente extraña, por más que necesaria (1).

El trabajo que aquí presento se plantea la posibilidad de abordar estos asuntos a través del examen de la variabilidad en los modelos de ocupación del espacio en la Edad del Hierro del noroeste. No se trata de reincidir en el análisis de los patrones de emplazamiento (Carballo, 1990). Éste va a ser sólo un elemento más que será tenido en cuenta para caracterizar y leer la forma en que las comunidades humanas han ido estableciendo su relación con el medio. No se trata tampoco de plantear una periodización más, sino de comprobar en qué medida las secuencias hasta ahora existentes, basadas en elementos diferentes al que se va a estudiar ahora, se corresponden en realidad con aspectos estructurales de la dinámica socio-político-cultural. Finalmente trataré de mostrar, de forma muy sintética,

(1) Tal vez quepa destacar el trabajo de X. Carballo (1996), especialmente en sus textos más recientes. algunas pautas para la revisión de este registro arqueológico.

\section{LOS MEDIOS}

\subsection{Objetos de trabajo}

El trabajo se fundamenta en el análisis de la distribución de yacimientos castreños en una zona en la que venimos trabajando desde tiempo atrás dentro de nuestro grupo de investigación (Santos et alii, 1997 o Parcero et alii, 1998). Se trata de un área de unos $200 \mathrm{~km}^{2}$ en torno al curso medio-bajo del río Lérez, provincia de Pontevedra (Fig. 1). Se localiza en la franja Oeste de Galicia, dentro de las tierras pre-litorales, cercanas a la faja costera y que ejercen de transición entre ésta y las tierras interiores. El relieve es en general abrupto, con fuertes pendientes y éscasez de superficies llanas (2).

Los 22 yacimientos castreños se reparten como se muestra en la figura 2 , en general en torno a las cuatro principales cuencas: Lérez, Umia, Almofrei y área de Cerdedo. De hecho algunos de ellos ocupan una posición periférica dentro de la zona seleccionada, con buena parte de sus entornos fuera del área de trabajo, lo cual implicará una consideración tan solo parcial de sus patrones de localización. Este efecto del límite escogido es inevitable, dado que si se hubiese ampliado o reducido dicha área, otros yacimientos ocuparían siempre una posición marginal y extrema, quedando parcialmente fuera del análisis (3). Por ello prestaré mayor atención a los yacimientos situados en su centro, funcionando los otros como 'documentación complementaria'.

\subsection{Consideraciones sobre el proceso de análisis}

La vía de análisis que voy a seguir es muy similar a la empleada por Fidel Méndez (1998: 162-69) en su caracterización del poblamiento de la Edad del Bronce de varias regiones de Galicia. Tanto las series de datos como los procedimientos concretos de

(2) Una descripción más detallada y un análisis del relieve de la zona en Santos et alii, 1997.

(3) Este problema, denominado en inglés edge effect, es un asunto bastantes veces tratado en relación con la aplicación de Sistemas de Información Geográfica a la arqueología (Leusen, 1999).

T. P., 57, n. $^{\circ} 1,2000$ 


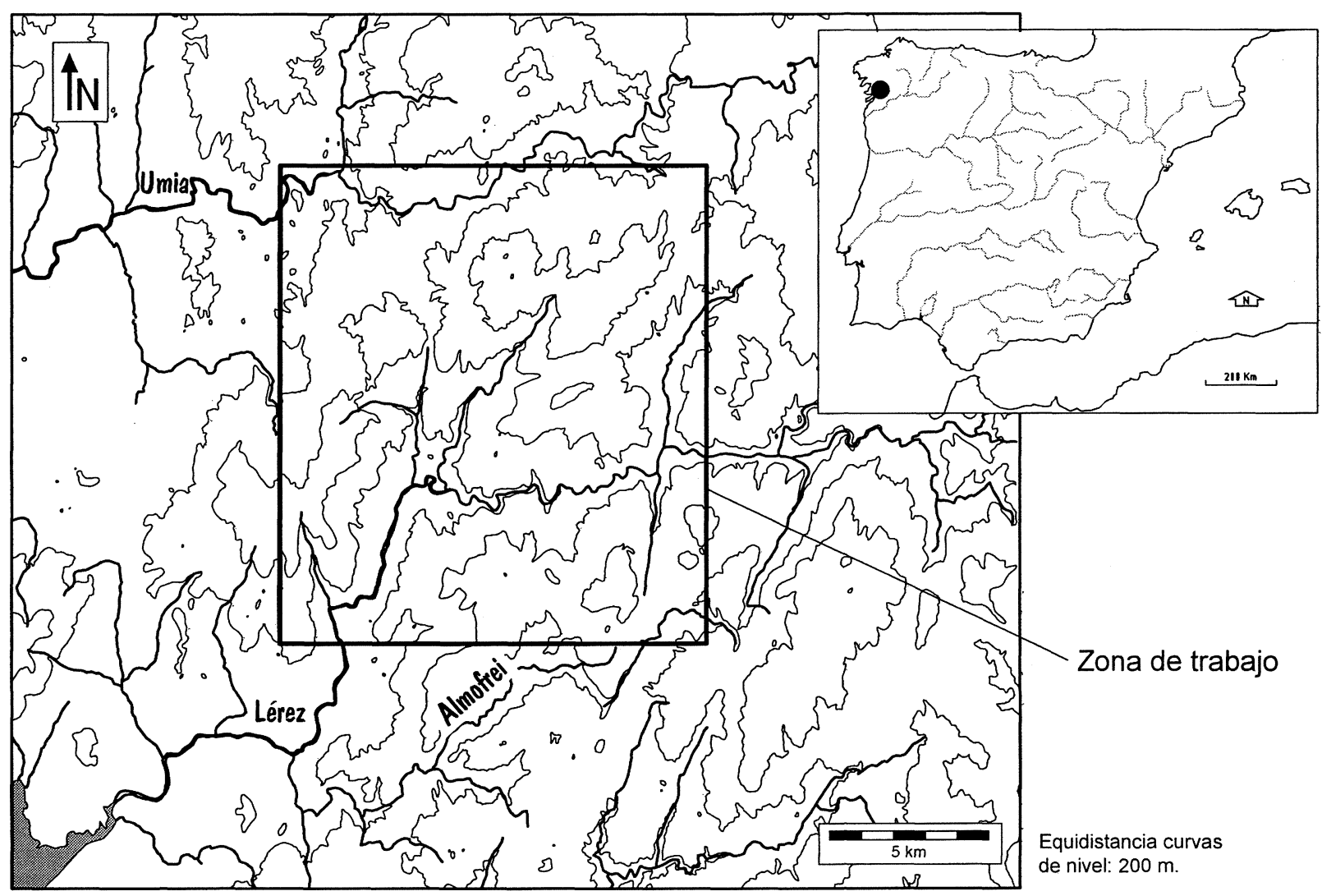

Fig. 1. Localización de la zona de trabajo en la Península Ibérica y en su contexto próximo.

análisis se encuentran allí bien comentados, por lo que haré simplemente una presentación elemental de todo ello.

El análisis comienza por la caracterización individualizada del emplazamiento de cada uno de los yacimientos. Como señala F. Méndez en el texto citado, tomar los objetos de trabajo de forma conjunta produce una visión uniforme de los mismos, haciendo imposible detectar posibles diferencias entre ellos. Una vez examinado y caracterizado cada yacimiento de forma individual, se hace una comparación entre ellos, tratando de extraer una serie de patrones de ocupación que agrupen a los castros con posiciones semejantes respecto al entorno. El siguiente paso consiste en cotejar los diferentes grupos así definidos con los rasgos formales de los yacimientos: dimensiones, tipo de estructuras artificiales, formas, puntos concretos de emplazamiento, etc. En la medida en que cada uno de los conjuntos guarde coherencia a nivel formal y de emplazamiento, las agrupaciones hechas resultarán significativas.

Una vez afianzados (o matizados) los distintos grupos de castros procederé a dotarlos de contenido, recurriendo, en lo posible, a información derivada de intervenciones arqueológicas directas en ellos. Esto nos pondrá en situación de pasar a la lectura interpretativa de los modelos que hemos definido.

\subsection{Las herramientas de trabajo}

Para desarrollar el proceso analítico he recurrido a uno de los útiles que más ha venido a renovar las investigaciones de índole espacial: los Sistemas de Información Geográfica (SIG). El empleo de un SIG permite, como es sabido, manipular gran cantidad de información de modo rápido y preciso, haciendo posible además la obtención de algunos resultados que de otro modo serían inviables. En todo caso la utilidad de los SIG en arqueología, como la de cualquier otra herramienta o procedimiento de análisis de la información, no puede desvincularse de la propia lógica de la investigación arqueológica; no basta con recolectar y sis- 


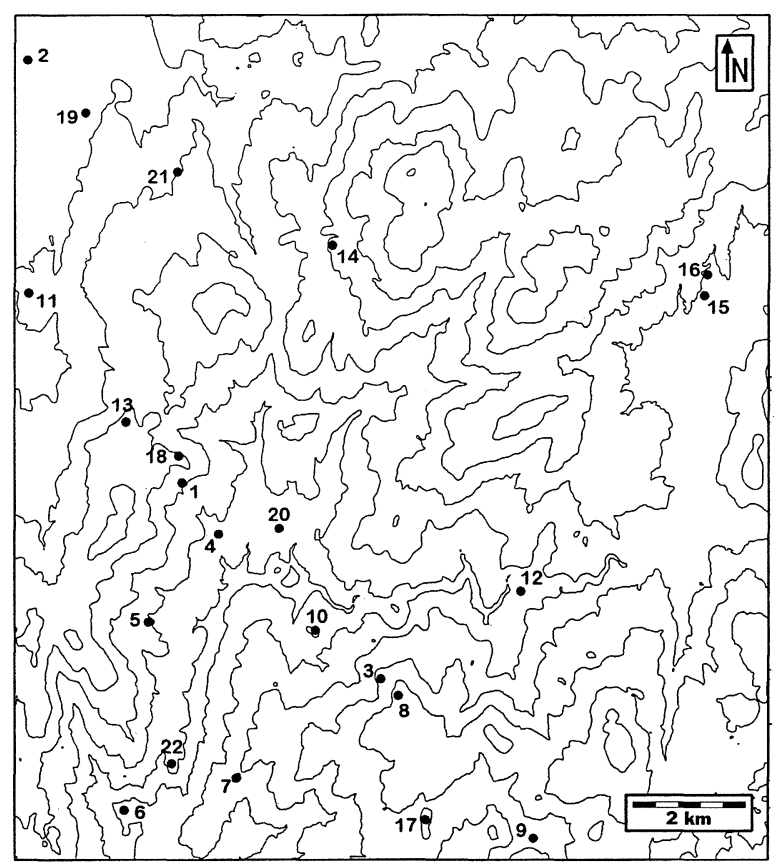

Fig. 2. Localización de yacimientos castreños en el área de trabajo: 1: A Devesiña; 2: A Igrexa; 3: A Sividá; 4: Campolameiro; 5: Cerdeiras; 6-Coto das Rodelas; 7: Coto do Castro; 8: Coto dos Mouros; 9: Cruz do Castro; 10: Fontán; 11: Gargantáns; 12: Louredo; 13: Monte Castelo; 14: O Castro; 15: Os Castros 1; 16: Os Castros 2; 17: Paraños; 18: Penalba; 19: Peroxa; 20: Praderrei; 21: Querguizo; 22: Redonde. Equidistancia curvas de nivel: $100 \mathrm{~m}$.

tematizar datos, o procesarlos a través de tecnologías más o menos complejas. El objetivo final debe ser siempre el dotar a esos datos de un significado, el producir interpretaciones basadas en ellos. Y para esto es necesario contextualizarlos en relación a un patrón de racionalidad o marco interpretativo; en mi caso, la Arqueología del Paisaje (Criado, 1993a, b).

Una de las reservas más habituales en los trabajos relacionados con la modelización artificial de procesos o situaciones reales es en qué medida se logra reproducir artificialmente esa realidad. Esto es especialmente frecuente en el caso de los trabajos hechos con SIG. La reproducción digital de relieves, paisajes, etc., ha sido vista siempre con cautela por parte de los propios investigadores que la propugnan y emplean de forma habitual (p.e. Leusen, 1999).Y es indudablemente cierto que los errores e imprecisiones son inevitables. Así, por ejemplo, un Modelo Digital del Terreno (MDT) es ante todo una representación de un terreno concreto, no su réplica idéntica. Pero hay una forma de salvar estos problemas. Partiendo de que nuestro proceso de análisis va a incluir errores con respecto al mundo real, lo único necesario para validar este proceso es que no pretendamos reproducirlo realmente. Es evidente que, por ejemplo, el ámbito de visibilidad de cada castro que más adelante se presenta no se corresponderá de forma idéntica (por razones de resolución, etc.) con el dominio visual real desde cada castro, que podríamos comprobar sobre el terreno (aunque los márgenes de error sean poco importantes). Lo relevante es que las imprecisiones van a ser equivalentes en todos los casos, ya que siempre se basan en un mismo MDT, un mismo algoritmo de análisis, etc. Dado que el objetivo no es reconstruir o reconocer el patrón real de localización de cada castro sino cotejar similitudes y diferencias entre ellos, las dificultades están salvadas. La gran ventaja de un SIG en este contexto es que permite manipular un volumen de información inabarcable de modo manual.

\subsection{Análisis de los patrones de localización de los castros}

Para valorar los criterios locacionales que han podido regir la elección de los emplazamientos de cada uno de los 22 castros de la zona de trabajo se han tomado en consideración los criterios que a continuación se detallan brevemente.

\subsubsection{Altitud relativa del yacimiento}

Uno de los rasgos que más y mejor han servido para identificar y definir un poblado castreño es su ubicación en altura, en un punto más o menos elevado y dominante. Habitualmente es cierto que los castros están enclavados por encima de las tierras que los circundan, si bien somos capaces de percibir sobre el terreno, y hasta de modelizar, que esta afirmación es matizable. ¿Podemos, entonces, llegar a reconocer en qué medida varía esta elevación en cada caso? Y ¿se mantiene este carácter dominante según nos vamos distanciando del yacimiento o es algo ceñido únicamente a su entorno más inmediato?

Lo que he denominado altitud relativa de los castros, al igual que los demás análisis efectuados en cada yacimiento, se ha calculado considerando dos intervalos de distancia sucesivos. El entorno inmediato se ha situado en un radio de $800 \mathrm{~m}$ alre-

T. P., 57, n. $^{\circ} 1,2000$ 
dedor de cada castro, límite de la posibilidad de distinguir a simple vista, por ejemplo, diferentes especies vegetales (Escribano, 1991: 84) (4). He situado a $2 \mathrm{~km}$ el entorno medio.

\subsubsection{Accesibilidad al entorno (y viceversa)}

Lo que he denominado accesibilidad, las condiciones de acceso desde un yacimiento a su entorno y viceversa, en una traducción a términos más habituales dentro del análisis arqueológico, podría corresponderse con el establecimiento de isocronas, si bien en este caso el tiempo no es el resultado inmediato sino una adaptación final.

Estudiar el desplazamiento en un espacio determinado requiere establecer los elementos que lo pueden dificultar. En este caso he tenido en cuenta dos: la pendiente, unánimemente reconocida como factor crítico en este tipo de análisis, y los cursos de agua. Podría haber sido igualmente tomada en consideración la cubierta vegetal del terreno o la presencia/ausencia de afloramientos rocosos. Sin embargo se trata de factores difíciles de valorar, bien por requerir un trabajo de documentación cartográfica de detalle (el segundo) o por desconocerse para el contexto original (el primero, que además es susceptible de modificación). En cambio pendientes y cursos de agua sólo pueden ser alterados a través de una inversión de trabajo a gran escala que supera, en general, la capacidad tecnológica disponible para el contexto en estudio.

El resultado final ha sido el establecimiento de cuatro categorías o intervalos de terrenos según su accesibilidad:

1. Alta, equivalente a la isocrona de 15 minutos.

2. Media, isocrona de 30 minutos.

3. Baja, isocrona de 45 minutos.

4. Mala: el conjunto de la superficie de la zona de trabajo no incluida en ninguna de las clases anteriores.

\subsubsection{Visibilidad}

El dominio visual desde cada uno de los castros es un factor que ha caracterizado muchas veces los emplazamientos castreños. Yo mismo me he referido a él (Parcero, 1995) como uno de los tres criterios esenciales que determinarían la elección de

(4) En realidad este límite se sitúa en $700 \mathrm{~m}$, pero lo he adaptado a 800 por cuestiones operativas de tipo matemático. un emplazamiento castreño, junto a la visibilización del lugar y sus condiciones defensivas.

He analizado su influencia mediante tres intervalos de distancia consecutivos: dos ya apuntados $(800 \mathrm{~m}$ y $2 \mathrm{~km})$ y un tercero que he llamado larga distancia, con límite en $15 \mathrm{~km}$, que es prácticamente el total de la longitud de la zona de trabajo.

\subsubsection{Potencialidad productiva del suelo}

La relación entre cada yacimiento y la potencial productividad de los terrenos de la zona en que se sitúan se ha establecido por medio de los datos derivados del libro y cartografía de Capacidad Productiva de los Suelos de Galicia (CPSG), elaborado por los profesores Díaz-Fierros Viqueira y Gil Sotres en el año 1984.

Una vez identificadas las distintas clases de suelo de la zona (19 en total), se han simplificado en tres grandes bloques para adaptarlas al análisis que nos ocupa. Dado que el factor crítico es la adaptación a condiciones tecnológicas primitivas, se han tenido en cuenta sobre todo la profundidad y el riesgo de encharcamiento del suelo:

1. Terrenos susceptibles de explotación intensiva, profundos y pesados pero que permiten mantener el cultivo bien sea en parcelas permanentes tipo huertas, con abonado sistemático, o bien en forma de rotaciones o barbechos de ciclo corto (régimen de año y vez, ampliamente empleado en Galicia hasta bien entrado el siglo XX en las áreas de campos permanentes o agras, Cardesín, 1992).

2. Terrenos susceptibles de explotación extensiva. Suelos ligeros, poco profundos y en general bien drenados, aunque habitualmente con importante sequía estival (sobre todo en la zona elegida). Serían las áreas más adecuadas para lo que tradicionalmente ha sido un aprovechamiento de monte: pastoreo extensivo, aprovechamientos secundarios y agricultura de barbecho de ciclo largo.

3. Terrenos improductivos, de pendientes extremas o carentes de suelo, sólo aptos para aprovechamientos indirectos tipo recolección, caza, etc.

Una vez establecidas estas categorías se ha cuantificado la presencia o ausencia de cada una de ellas en los intervalos siguientes:

- Terrenos existentes a corta y media distancia $(800 \mathrm{~m}$ y $2 \mathrm{~km})$.

- Terrenos visibles a corta y media distancia.

- Terrenos de accesibilidad alta (hasta 15 minutos). 
- Terrenos preferentes, esto es, accesibles hasta 15 minutos y visibles.

\section{EL ANÁLISIS DE LOS YACIMIENTOS}

Como podrá suponerse, los datos manejados suponen un volumen muy importante y es inviable presentarlos todos aquí. Lo que sigue es simplemente una muestra de algunos de los resultados más significativos, con cierto grado de síntesis y habiendo eliminado el ruido innecesario.

\subsection{Altitud relativa}

Como se puede apreciar en los gráficos adjuntos, hay una diferencia bastante sustancial según el intervalo de distancia que se considere. Así, en relación al entorno más inmediato -radio 800 m-, la práctica totalidad aparecen en puntos situados por encima de la mayor parte del terreno circundante (Fig. 3), aunque obviamente hay diferencias de grado. Pero parece más revelador el examen del gráfico que muestra la altitud relativa de los castros con respecto a las áreas circundantes en un radio de 2 km (Fig. 3). Muchos de los castros que a corta distancia aparecían como fuertemente dominantes sobre el entorno suavizan o incluso invierten esta tendencia según nos vamos distanciando de ellos. Así, casos como $\operatorname{los}^{\circ}{ }^{\circ}$ 6, 22, 20 ó 10 son muy significativos (5). Se trata de yacimientos ubicados en puntos elevados y prominentes, pero únicamente a escala de detalle. Sin embargo hay otro conjunto de yacimientos que no sólo siguen siendo dominantes a media distancia, sino que incluso lo son más que en relación con sus áreas más cercanas. Destacan a este respecto seis yacimientos: $\mathrm{n}^{\circ} 7,18,8,13,17 \mathrm{y}$ 3 , a los que se suman, con menos claridad, $\operatorname{los} \mathrm{n}^{\circ} 14$ y $19(6)$.

\subsection{Accesibilidad}

Igual que la visibilidad, la facilidad de acceso al entorno puede ser evaluada desde dos puntos de vista. El primero es cuantitativo: cuánto terreno es

(5) En adelante los yacimientos se numeran según aparecen en la figura 2.

(6) Esta posición dominante en términos relativos no siempre es coincidente con una superior altitud absoluta del yacimiento; así el caso de Coto do Castro $\left(\mathrm{n}^{\circ} 7\right)$, uno de los más dominantes y sin embargo tan sólo el décimo en cuanto a altitud absoluta.

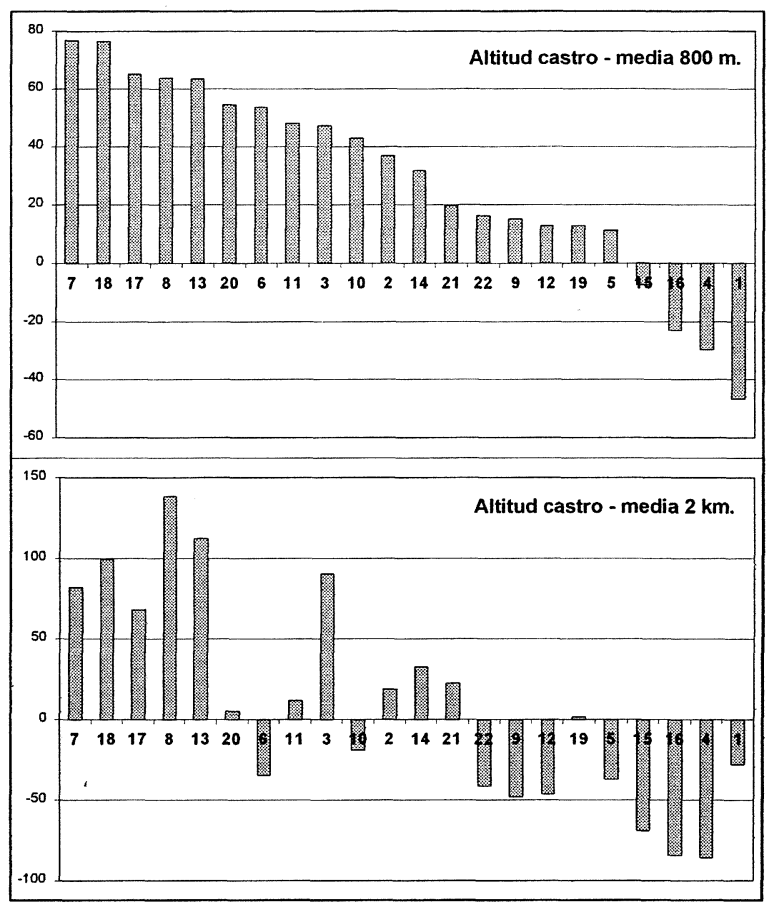

Fig. 3. Cuantificación de la altitud relativa de los castros con respecto a su entorno de $800 \mathrm{~m} \mathrm{y} 2 \mathrm{~km}$.

accesible invirtiendo un esfuerzo equivalente. El segundo es cualitativo: qué tipo de terrenos son los accesibles. El segundo resulta más revelador.

Aquí surge de nuevo una dualidad notable, que ejemplificaré con los castros de Praderrei $\left(\mathrm{n}^{\circ} 20\right)$ y Penalba $\left(n^{\circ} 18\right)$ (Fig. 2), porque están entre los que mejor muestran todo el conjunto de rasgos que definen cada modelo. Ambos presentan ciertas divergencias en cuanto a la superficie accesible; así desde Praderrei $\left(\mathrm{n}^{\circ} 20\right)$ es posible acceder en 15 minutos a casi el doble de terreno que desde Penalba $\left(\mathrm{n}^{\circ} 18\right)$ : 0.92 y $0.51 \mathrm{~km}^{2}$ respectivamente, aunque según aumenta el tiempo de desplazamiento las cifras se acercan hasta hacerse semejantes en la isocrona de 45 minutos (10.93 y $\left.9.3 \mathrm{~km}^{2}\right)$.

Pero las verdaderas divergencias surgen al comprobar por dónde se distribuyen esas superficies accesibles (Fig. 4). Desde el poblado de Praderrei hay una accesibilidad general y equivalente en casi todas direcciones, que se mantiene en cualquiera de los tres intervalos de tiempo que tomemos. Para Penalba las zonas más inmediatamente accesibles (hasta 30 minutos) claramente se concentran en dirección oeste. Tan sólo a partir de la media hora de camino empieza a igualarse la facilidad de acceso en todas direcciones. La inversión de tiempo en el desplazamiento a partir del castro de Penalba es,

T. P., 57, n. $^{\circ} 1,2000$ 


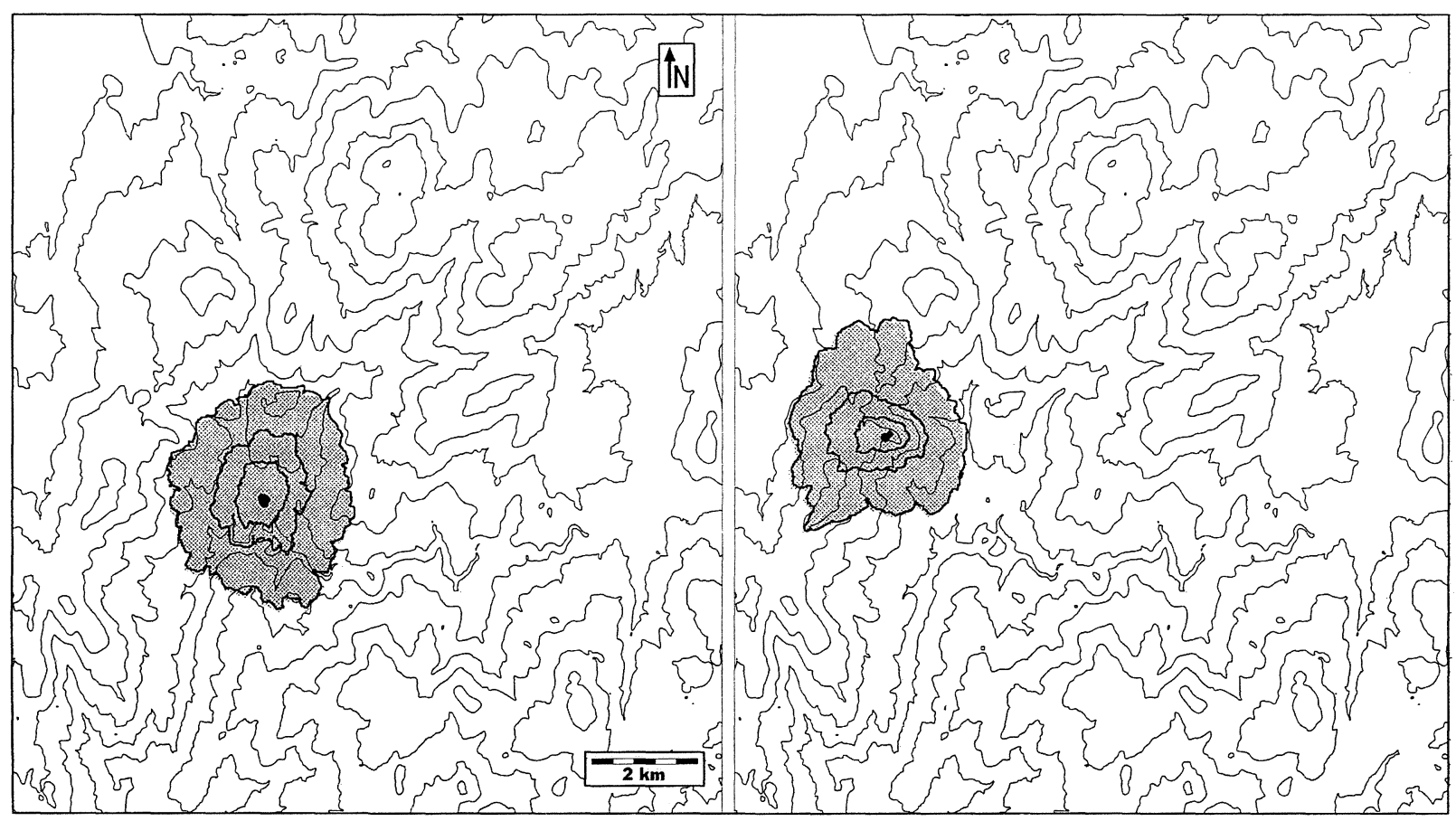

Fig. 4. Dos modelos de accesibilidad al entorno: isocronas de 15, 30 y 45 minutos desde los castros de Penalba $\left(n^{\circ} 18\right.$, derecha) y Praderrei ( $\left.n^{\circ} 20\right)$.

pues, muy desigual; así con el mismo esfuerzo podemos recorrer, por ejemplo, $1.200 \mathrm{~m}$ hacia el oeste frente a los sólo $650 \mathrm{~m}$ hacia el este o los poco más de $500 \mathrm{~m}$ hacia el norte.

Cada uno de estos dos yacimientos ejemplifica un modelo de movilidad. Al modelo desigual de Penalba se suman los castros $n^{\circ} 8,17,13$ y 7 , así como aquellos localizados en las inmediaciones del Lérez ( ${ }^{\circ} 6,12$ y 22); al modelo de Praderrei se pueden asignar, con matices y cierta variabilidad, el resto.

\subsection{Visibilidad}

Los gráficos adjuntos muestran la superficie de terreno visible desde cada yacimiento (Fig. 5). He excluido aquellos con un porcentaje significativo de su entorno más cercano fuera de la zona de trabajo, que por ello sólo puedan ser parcialmente cuantificados (7). Llama la atención la dualidad entre visibilidad a corta o media distancia y más allá de $2 \mathrm{~km}$ A corta y media distancia algunos castros se destacan de forma notable, existiendo en general un do-

(7) En el gráfico de larga distancia figuran en claro aquellos castros cuya superficie visible se continúa de forma importante más allá de la zona de trabajo. minio visual de entre el $50 \%$ y el $75 \%$ del entorno. Pocos son los ejemplos que escapan a esta media, casi ninguno por arriba y algunos por abajo.

La situación es bastante dispar en el gráfico que muestra la visibilidad a larga distancia, ya que sólo un grupo de cuatro alcanzan a divisar más de 30 $\mathrm{km}^{2}$ : Penalba, Coto dos Mouros (éste con un marcado salto respecto a la visibilidad inmediata), A

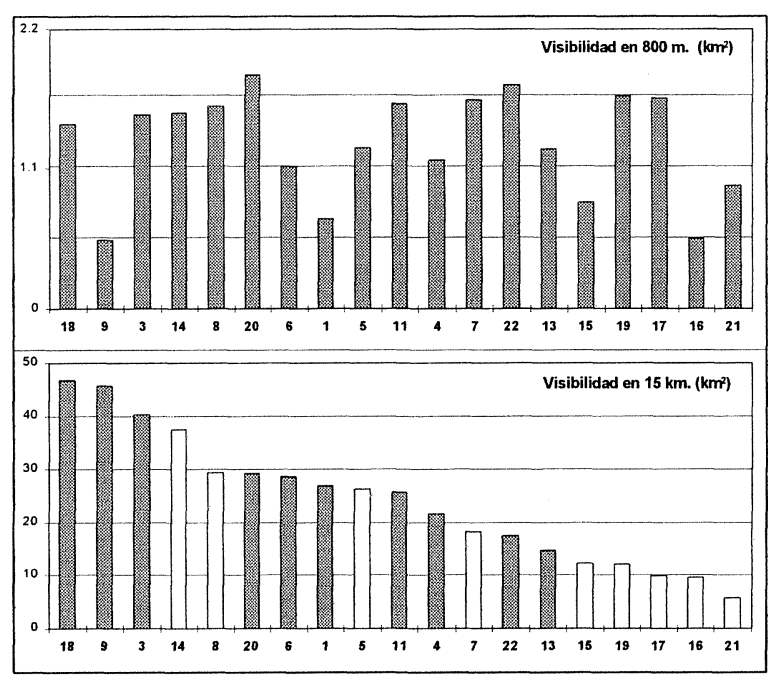

Fig. 5. Superficie en $\mathrm{km}^{2}$ visible desde cada castro a corta $(800 \mathrm{~m})$ y larga distancia $(15 \mathrm{~km})$. 


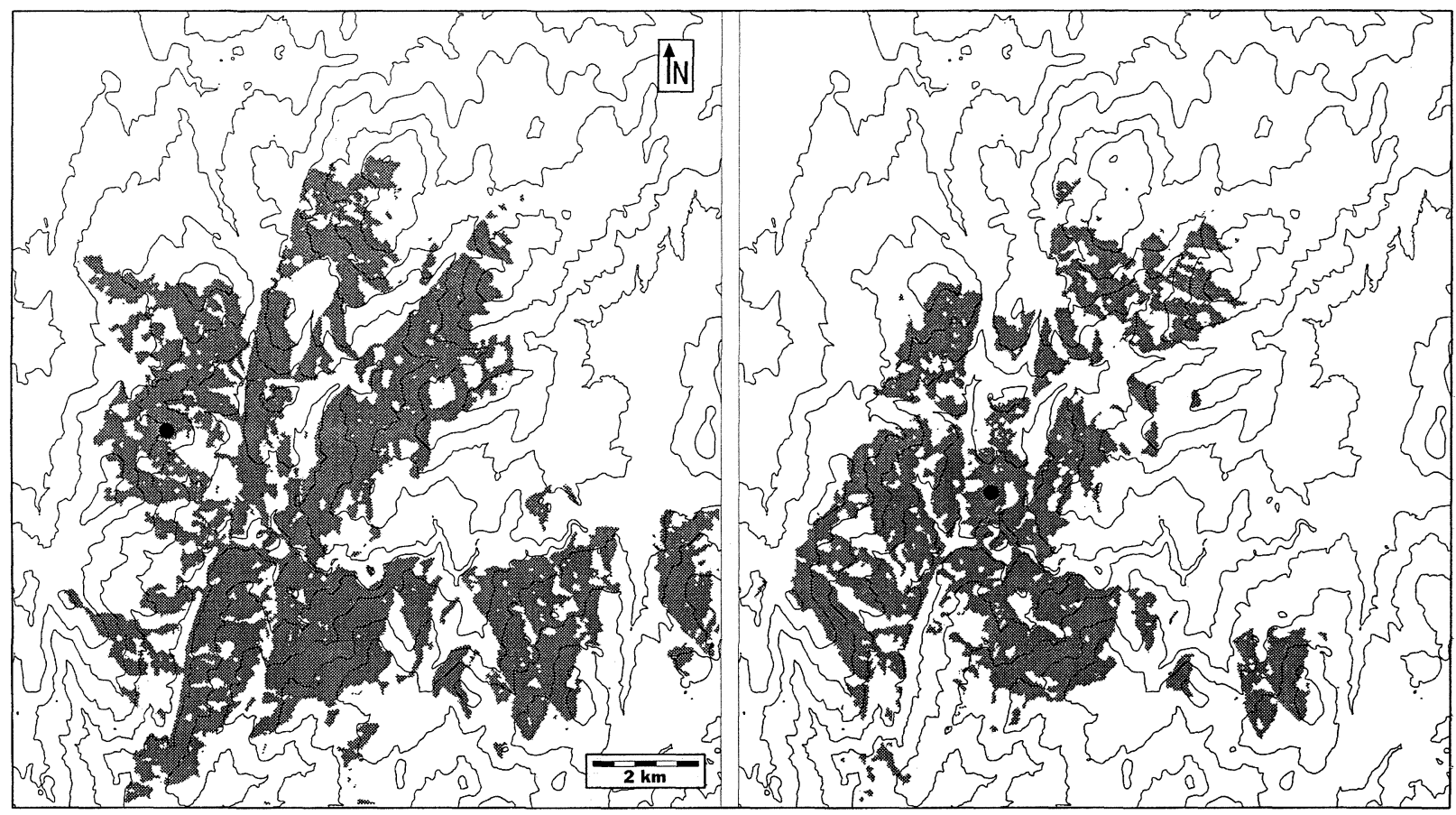

Fig. 6. Dos modelos de visibilidad: castros de Penalba y Praderrei.

Sividá y Monte Castelo (nº 18, 8, 3 y 13). A ellos puede añadirse Coto do Castro $\left(\mathrm{n}^{\circ} 7\right)$, que ronda esa cifra con una parte significativa de su abanico visible fuera de la zona analizada, y Paraños $\left(n^{\circ} 17\right)$, con una cantidad muy baja pero bastante falseada por su posición periférica.

Al igual que ocurría con la accesibilidad, es tanto o más significativo examinar cómo se reparten esas zonas visibles. Recurriré a los mismos paradigmas: Penalba y Praderrei (Fig. 6). La situación es similar a la de la accesibilidad, pero inversa. Penalba extiende su dominio visual en un claro abanico norte-sur, interrumpiéndose hacia el oeste a escasa distancia, mientras Praderrei ofrece un reparto más homogéneo y radial. La inversión respecto a la accesibilidad es que las zonas más visibles desde Penalba son las más inaccesibles desde el castro. Esta diferencia cualitativa se corresponde también con una diferencia cuantitativa: la visibilidad radial de Praderrei se concentra mucho en su entorno más inmediato y es menor a larga distancia, mientras que los castros que siguen el modelo de Penalba prescinden de dominar visualmente buena parte de sus terrenos circundantes pero alcanzan grandes superficies a larga distancia.

El modelo parcial de Penalba es seguido, en condiciones parejas, por Monte Castelo, Coto dos Mouros, Coto do Castro, Paraños y O Castro ( $\mathrm{n}^{\circ} 13$,
$8,7,17$ y 14). El resto de castros muestran una visibilidad más o menos radial y más reducida a larga distancia.

\subsection{Potencialidad productiva del entorno}

Siguiendo con los mismos ejemplos, se muestra en la figura 7 el reparto de clases de suelos en el entorno inmediato y medio de Penalba y Praderrei. Como se puede apreciar, en términos absolutos en

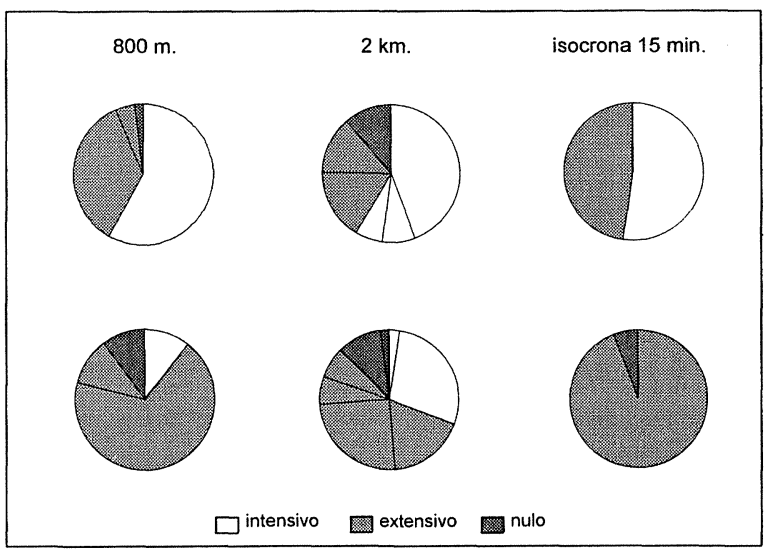

Fig. 7. Potencialidad productiva del suelo en el entorno de los castros de Penalba y Praderrei. Los gráficos representan clases de suelos agrupadas según su aptitud. 
Penalba predominan las zonas de potencial aprovechamiento extensivo, con un porcentaje significativo de terrenos de difícil o nula productividad, y en Praderrei los terrenos de posible utilidad intensiva. Además en Praderrei el aumento de la distancia respecto al castro no altera significativamente el reparto de los tipos de suelo, cosa que sí ocurre de forma nítida en Penalba, donde además hay un salto en la variedad de terrenos disponibles.

Un nuevo elemento de contraste lo obtenemos al examinar cómo influye la accesibilidad sobre el tipo de suelos disponibles. En el caso de Praderrei la proporción de suelos en las zonas accesibles y en términos absolutos es prácticamente la misma, debido sobre todo, como se vio, a una accesibilidad radial, global y homogénea a todo el entorno. En Penalba, sin embargo, la variabilidad en las condiciones de acceso incide en una reducción de la variedad de terrenos disponibles. Además de esta reducción es claro que hay, entre estas zonas con mejor accesibilidad, un peso importante de los terrenos de nula o muy baja productividad.

Así pues, las divergencias son también muy claras a este nivel. Es aquí, además, donde se hace significativo ese diferente patrón de accesibilidad al entorno que se examinó más arriba: no sólo es importante la diferencia cuantitativa, la mayor o menor facilidad de movimiento sobre el terreno a partir del castro, sino también, y sobre todo, la cualitativa, cuáles son las zonas más estrechamente vinculadas al castro.

\subsection{Recapitulación}

Recogiendo los resultados del análisis individual de cada yacimiento y las correlaciones expuestas se pueden establecer de forma nítida dos modelos de localización de los poblados castreños.

El primer modelo está constituido por yacimientos situados en puntos que destacan de su entorno inmediato y dentro de un área de, al menos, $2 \mathrm{~km}$ de radio. Tienen una altitud relativa siempre positiva, y en buen grado, con respecto a los terrenos circundantes. Esta posición dominante les permite disponer de un control visual amplio a larga distancia. Sin embargo, y paradójicamente, el control sobre las áreas más cercanas es bastante desigual y no demasiado intenso. Esta visibilidad a corta y, en menor medida, media distancia, es discontinua y adopta una disposición en abanico: no hay una visibilidad genérica y homogénea en todas direcciones sino que se prima el dominio visual de un arco determinado en perjuicio de las restantes direcciones. Hay, pues, una clara dualidad tanto cuantitativa, en función de la distancia (irregular y parcial en las inmediaciones frente a una gran amplitud a larga distancia), como cualitativa, concentrándose el dominio visual en ciertas direcciones en detrimento de otras.

Las condiciones de acceso al entorno se caracterizan por una dualidad opuesta a la de la visibilidad. Se registra una oposición entre un sector concreto del entorno fácilmente accesible desde el castro y zonas circundantes de difícil movilidad. La ubicación de estas zonas suele invertir la pauta marcada por la visibilidad, y así los terrenos más accesibles desde el castro suelen situarse en posiciones de menor visibilidad.

Finalmente estos castros se sitúan en lugares en los que la aptitud potencial preferente del medio es de tipo extensivo. El entorno más inmediato de los poblados se caracteriza por el predominio de suelos ligeros, poco profundos, en general bien drenados y de pendiente ligera o moderada. Son también habituales las zonas de difícil aprovechamiento o incluso improductivas. Otro rasgo destacado es que, según nos vamos alejando del poblado, la variedad de ambientes y de potenciales aprovechamientos se incrementa mucho, con lo que suele haber un contraste fuerte entre la variedad de suelos disponibles a $800 \mathrm{~m}$ y $2 \mathrm{~km}$ del castro, así como en el peso porcentual de cada clase de terreno en ambos intervalos. No parece que la presencia inmediata y accesible de terrenos aptos para la explotación intensiva sea un criterio primordial para seleccionar la localización.

Pertenecerían a este primer grupo Monte Castelo, Penalba, Coto do Castro, Paraños, Coto dos Mouros, O Castro y A Sividá (nº 13, 18, 7, 17, 8, 14 y 3 ).

El segundo modelo lo constituyen yacimientos con posiciones que, si bien son en general dominantes sobre el entorno más inmediato, se muestran más discretas a medida que nos alejamos. Así, la altitud relativa en los primeros $800 \mathrm{~m}$ suele ser positiva, incluso bastante, pero al tomar en consideración un radio mayor de terreno $(2 \mathrm{~km})$ desciende mucho hasta hacerse neutra o en muchos casos negativa.

La visibilidad desde los castros de este grupo es habitualmente intensa en las zonas más cercanas, rara vez inferior al $50 \%$ del terreno, pero se detiene en unos valores medios o bajos a larga distancia, 
siempre por debajo de $30 \mathrm{~km}^{2}$. A diferencia del grupo anterior, la visibilidad es circular, se distribuye homogéneamente en torno al yacimiento.

Las áreas accesibles suelen ser, a igualdad de esfuerzo/tiempo, más amplias que las del grupo anterior. Sin embargo la verdadera diferencia viene dada por su disposición y ubicación, coincidente con su visibilidad: el desplazamiento a partir del castro es prácticamente igual de fácil (o de difícil) en cualquier dirección. Son excepción los yacimientos situados en el borde del Lérez que, lógicamente, cuentan con un obstáculo casi insalvable en esa dirección. La coincidencia entre áreas visibles $\mathrm{y}$ accesibles es generalmente muy amplia.

Finalmente, en cuanto a la potencialidad productiva del entorno, predominan las superficies de potencial aprovechamiento intensivo, suelos más profundos y fértiles, con menor incidencia de la sequía estival, bajo riesgo de heladas y grados de pendiente suaves o ligeros. Además, la variedad de suelos disponible no suele cambiar de forma significativa al aumentar la distancia al poblado y los gráficos de clases de suelos en $800 \mathrm{~m}$ y $2 \mathrm{~km}$ son bastante homogéneos.

Dentro de este segundo modelo encajan los restantes 15 yacimientos: A Igrexa, Peroxa, Querguizo, Gargantáns, A Devesiña, Praderrei, Campolameiro, Cerdeiras, Fontán, Redonde, Coto das Rodelas, Louredo, Os Castros 1 y 2, Cruz do Castro (8).

\subsection{Correlación entre los modelos de localización y los rasgos formales de los yacimientos}

Antes de interpretar estos modelos de localización es posible corroborar que se trata de una diferenciación significativa, no casual, a través del recurso a otros indicios, como sus rasgos formales.

Seis de los siete castros que responden al primer modelo de localización coinciden también en su morfología: Monte Castelo, Penalba, Coto dos Mouros, Paraños, O Castro y Coto do Castro, caracterizados por su sencillez formal. Se trata de castros de recinto único, carentes de los muchas veces característicos elementos adicionales como antecastros, terrazas, recintos exteriores, etc. Son además

(8) Este grupo es tal vez algo más heterogéneo que el anterior y sería posible introducir algunos matices, aunque en esencia todos estos yacimientos cumplen los rasgos que se acaban de definir. de pequeño tamaño, ninguno por encima de $1 \mathrm{Ha}$. de superficie útil, y muy similares (9).

La posición prominente de estos castros los hace muy visibles a media y larga distancia, apareciendo por lo general recortados en el horizonte visual desde casi cualquier punto. Esta prominencia visual es debida sobre todo al propio emplazamiento del poblado, ya que sus estructuras artificiales son sobre todo $-\mathrm{y}$ este es otro rasgo característico- de tipo negativo. Así, estos castros aparecen definidos sobre todo por aterrazamientos y fosos, a veces de entidad, que han implicado una importante inversión de trabajo y una importante alteración del lugar, pero carecen de murallas o parapetos muy resaltados. Este tipo de alteración artificial del paisaje, que es un elemento sustantivo de todo yacimiento castreño, no parece haber requerido de la erección en positivo de volúmenes de tierra que constituyan nuevas líneas visuales de carácter artificial (10). Esta circunstancia es muy clara si nos situamos en el interior de cualquiera de estos poblados: desde el centro es posible ver hacia fuera, la visibilidad no está constreñida a sus límites.

Los castros agrupados en el segundo modelo de localización, así como el de A Sividá, muestran rasgos formales diferentes. Son más complejos, aunque haya que entender aquí la complejidad de forma matizada. Se componen de un recinto central que se complementa con alguna o algunas estructuras adicionales como terrazas, antecastros, etc. (11). Las dimensiones del conjunto, sin ser nunca muy notables, sí son por término medio superiores a las de los yacimientos del grupo anterior, en función sobre todo de esa existencia de estructuras añadidas. Su apariencia formal se corresponde

(9) A Sividá ( $n^{\circ} 3$ ) es la única excepción ya que, si bien responde a este tipo de localización, formalmente corresponde al segundo modelo. Tiene, además, otros componentes excepcionales como su tamaño (es holgadamente el mayor de la zona), entidad del sistema defensivo, topónimo (adaptación de Cividá - Ciudad) único en el área, y la existencia en su interior de una gran roca grabada con motivos poco habituales y que podrían ser contemporáneos al yacimiento. Por todo ello parece tratarse de un poblado excepcional, seguramente un "lugar central" del Hierro II, aunque este asunto desborda las ambiciones de este artículo y demanda un trabajo diferente.

(10) Hay que hacer notar que alguno de estos yacimientos, en concreto Paraños (17) y Coto dos Mouros (8), sí conserva restos de muralla, pero, a juzgar por el volumen actualmente visible de sus derrumbes, no parece que hubiesen alcanzado gran altura.

(11) Esto depende en gran medida de las condiciones de conservación de cada yacimiento, ya que hay que recordar que muchos de ellos están en zonas de intensa ocupación humana tradicional y actual, lo que en ocasiones ha alterado de forma grave su apariencia.

T. P., 57, n. ${ }^{\circ} 1,2000$ 
con lo que suele ser característico: recintos delimitados por parapetos, a veces con fosos anejos y en algunos casos con restos de sistemas de acceso.

Ocupan puntos que son menos prominentes a media o larga distancia, y por ello menos visibles desde el exterior. Esto se compensa con la existencia de esos elementos de delimitación y defensa que, ahora sí, emergen artificialmente del terreno constituyendo hitos marcados en el paisaje que, en su apariencia original, habrían actuado como reclamos visuales. Esta diferente visibilización del poblado se corresponde con una también distinta conformación interior; las defensas suelen actuar como cinturones cerrados que limitan por completo la visibilidad de la que se puede disfrutar desde el interior de la aldea. En estos casos la única forma de disfrutar de la panorámica visual sería subiéndose a las defensas. La sensación interior es la de un espacio cerrado y limitado, bastante escaso por otra parte.

\section{LECTURA, O EL CONTENIDO DE LOS MODELOS}

En el estado actual de esta investigación parece que una lectura de tipo "cronológico" permitiría dotar de sentido a los modelos de localización que se han identificado. El primero de los modelos definidos se correspondería con lo que en la mayor parte de las periodizaciones empleadas se denomina Castreño Inicial o Fase formativa de la cultura castreña (Fariña et alii, 1983; Silva, 1986; Martins, 1988; Peña, 1992b;Alarçâo, 1992; Peña yVázquez, 1996). Traducido a términos más generales, se trata del modelo de ocupación del espacio en la Primera Edad del Hierro. Obviamente, el segundo de los modelos se correspondería con el período inmediato posterior, la Segunda Edad del Hierro, incluyendo, por las razones que luego se detallan, el mantenimiento de la ocupación castreña bajo dominio romano y alcanzando hasta el estadio final de la misma. Esta lectura "cronológica" no implica recurrir al tiempo como argumento significativo; me refiero al tiempo de forma convencional, como introductor de la significación completa de estos modelos, ya que es la dinámica sociocultural la que ha creado dos modelos diferentes que se objetivan ante todo en dimensiones espaciales y que, desde nuestra posición, comprendemos cronológicamente (12).

(12) Ajustada precisión que debo a Felipe Criado.
Los argumentos que permiten sostener esta lectura son de dos tipos. Por una parte se puede recurrir a la comparación con modelos como el definido por X. Carballo (1990) en el valle del Ulla. Su trabajo puede emplearse como herramienta de contraste ya que uno de sus resultados más significativos fue el establecimiento de una secuencia temporal para los poblados castreños a partir del examen de un aspecto sobre el que este trabajo pasa un poco tangencialmente: el emplazamiento, entendido como la observación formal de los puntos concretos en que se sitúan los castros. Según Carballo los castros con ocupaciones tempranas (siglos VIII$\mathrm{V}$ a.C.) suelen disponerse en los emplazamientos que él categoriza como tipos A y C: cumbres y espolones bien destacados. Vistos así, puede observarse como cuatro de los poblados que he encuadrado en el primer modelo (Penalba, Monte Castelo, Coto do Castro y Paraños) responden perfectamente a este tipo de emplazamiento. El quinto, Coto dos Mouros, ocupa un punto un tanto más peculiar, aunque asimilable a ellos. Los demás se adscriben a alguno de los modelos que Carballo sitúa en las fases II y III del mundo castreño (siglos IV-II a.C. y I a.C.-II d.C.): media ladera o elevaciones en medio de zonas abiertas y bajas.

Pero todavía es posible una contrastación más directa en algún caso. Sólo existe información estratigráfica de dos de los castros que he estudiado: Penalba y Monte Castelo. Penalba fue excavado en los años 80 por A. Álvarez $(1986,1987)$, lo que permitió constatar su ocupación temprana, con materiales y estructuras propias de esa primera fase del castreño. Existen además varias dataciones de C-14 que confirman este extremo (Carballo y Fábregas, 1991). Monte Castelo, únicamente fue sondeado de forma puntual por el propio A. Álvarez (1987). Los datos disponibles apuntan a una ocupación igualmente temprana, dentro también del Hierro I.

\subsection{Implicaciones: las edades del hierro}

Como se ha apuntado, el esquema vigente de partición cronológica de la cultura castreña del noroeste, cualquiera que sea la propuesta concreta que se tome, establece tres etapas esenciales. En la zona de trabajo ahora elegida y a nivel de modelos de ocupación del espacio únicamente se pueden distinguir dos, y entre ellas parece establecerse una clara discontinuidad. 


\subsubsection{La ocupación en el Hierro I}

El modelo de ocupación del Hierro I parece corresponderse con la ruptura del sistema vigente en la Edad del Bronce, aunque todavía sin la conformación definitiva de una nueva forma de paisaje. Por una parte, y como rasgo estructural esencial que señala una nítida línea divisoria con la situación precedente, el sistema de comunidades semi-móviles vigente a lo largo de toda la Edad del Bronce es reemplazado, por primera vez, por poblados que se fijan de forma permanente al territorio. Por primera vez se asiste a la inversión masiva de trabajo colectivo en la construcción de un poblado, que incluye la alteración sustancial del paisaje precedente a través de obras como aterrazamientos o profundos fosos defensivos. Este cambio, por encima de cualquier continuidad en aspectos menores del sistema socio-cultural (que existen, como veremos), implica la necesidad de reconocer que estamos ante una nueva forma de concebir no sólo las relaciones entre el ser humano y el paisaje sino de estructurar y gestionar a las propias comunidades. Hablar, pues, de castros con ocupaciones del Bronce Final, como es habitual en muchas publicaciones, equivale a conceder una importancia impropia a aspectos tales como las formas de la metalurgia o las técnicas de decoración de la cerámica, por ejemplo.A no ser, claro está, que se prefiera seguir manteniendo a toda costa esquemas periodizadores puramente tipológicos y carentes de contenido (13).

Sin embargo, como se apuntó, el modelo generado en el Hierro I mantiene elementos ya existentes en la situación anterior. Además de asuntos formales como la concepción global de la cultura material, sobre todo la cerámica (Cobas, e.p.; Cobas y Prieto, 1998), parece que todavía no se da el salto definitivo a una fuerte intensificación agraria. Es bien cierto que hay cambios al respecto, como por ejemplo la aparición del cultivo de cereales como el mijo, que permiten asegurar la obtención de una doble cosecha anual complementando a la de cereal de invierno (14). Sin embargo esta doble explotación anual parece haberse desarrollado todavía con una tecnología similar a la de la Edad del Bronce, esto es, con laboreos extensivos de ciclo largo; es

(13) La argumentación tras este párrafo fue desarrollada por mí mismo y Fidel Méndez en una comunicación inédita titulada Analysis of the rise of fortification in the Northwest of Iberia presentada en la primera reunión anual de la European Association of Archaeologists en Santiago de Compostela (1993).

(14) Semillas de mijo han aparecido en abundancia, sin ir más lejos, en el castro de Penalba (Álvarez, 1986).

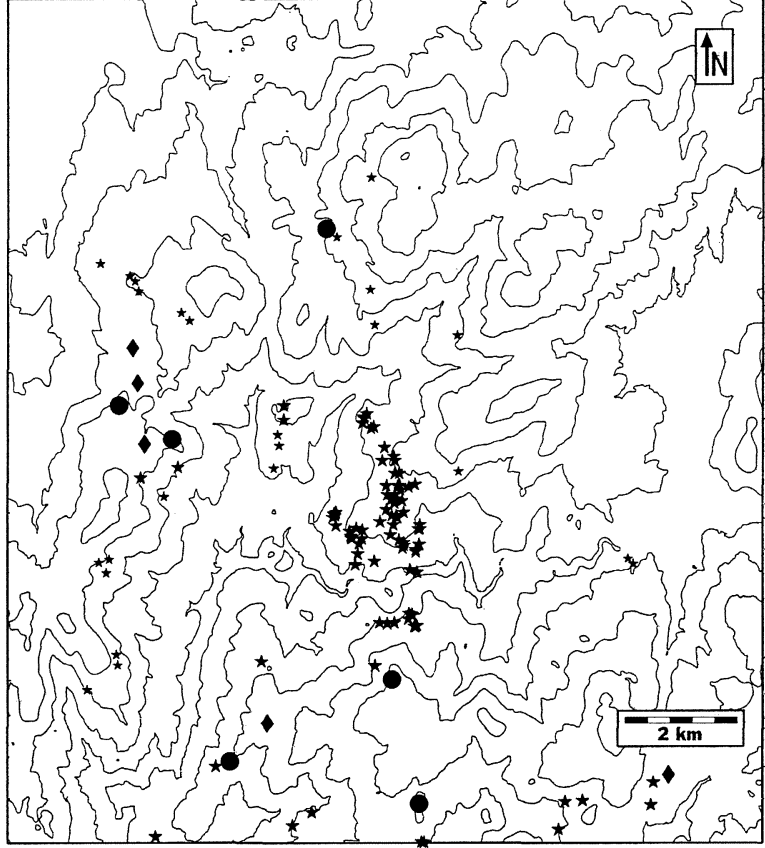

Fig. 8. Vinculación entre los yacimientos de probable adscripción al Hierro I y otros elementos arqueológicos: petroglifos (estrellas) y asentamientos (rombos) de la Edad del Bronce.

un salto cualitativo, pero aún no definitivo. Esto puede apreciarse si se observa la distribución de castros del Hierro I en asociación con los asentamientos conocidos en la zona de la Edad del Bronce y con los petroglifos (Fig. 8) (15). Confirmando el modelo propuesto por F. Méndez (1994) estos poblados de la Edad del Bronce ocupan zonas en general altas, caracterizadas por suelos ligeros y bien drenados y por la existencia de cubetas húmedas (brañas) como reservas estivales de pasto. M. Santos (1998) ha aportado un nuevo elemento al proponer que muchas veces los petroglifos con motivos propios de la Edad del Bronce se sitúan en las zonas de acceso a esas áreas generalmente elevadas que ocupan los poblados, actuando como delimitadores territoriales de los espacios propios de cada comunidad o pequeño grupo de comunidades. Como se puede apreciar en la figura 8 , los castros que responden al modelo de localización de este Hierro I ocupan posiciones destacadas en el extremo de esas zonas altas en las que, además, hay documentados asentamientos de la Edad del Bronce.

(15) Únicamente se conocen algunos poblados de la Edad del Bronce en este área, todos ellos a partir de las obras de seguimiento arqueológico del Oleoducto Coruña-Vigo; esto es patente en la distribución lineal de los yacimientos en el mapa. 
De hecho son estos seis castros los únicos de los 22 del conjunto que están emplazados a menos de $1 \mathrm{~km}$ de distancia de algún petroglifo, a pesar de la gran densidad de rocas grabadas en la zona (16).

Esta vinculación de los castros tempranos con las zonas sujetas a ocupación y explotación en la Edad del Bronce se confirma si examinamos cuáles son las zonas más accesibles desde ellos (Fig. 9). Es muy clara la relación de proximidad de estos castros con esas zonas altas. Ello permite suponer que sean estas áreas de suelos ligeros y fáciles de trabajar con una tecnología más rudimentaria las que sigan siendo todavía en este momento escenario del aprovechamiento por parte de unas comunidades todavía en vías de conquistar definitivamente las tierras bajas.

Por otra parte la quiebra del sistema de ocupación y explotación vigente en la Edad del Bronce se produce con un matiz muy importante: la fortificación de los lugares de habitación. Frente a un modelo de asentamiento abierto, localizado en el centro de esas zonas llanas, en puntos incluso deprimidos del paisaje (Méndez, 1994, 1998), el paso a este Hierro I supone no sólo el traslado de los poblados al extremo del sistema, sino su ubicación en puntos más o menos inaccesibles, inaccesibilidad reforzada a través de la construcción de elementos artificiales como fosos o terraplenes. Dejando ahora al margen la debatida vinculación de las defensas castreñas con unas comunidades más o menos guerreras, lo cierto es que el cambio implica una indudable preocupación por proteger y aislar tanto a las poblaciones como a sus bienes del mundo exterior, que constituye una amenaza, real o ficticia.

La propia localización de los castros del Hierro I en el extremo de las zonas altas, en el balcón de las cimas, funciona como ilustrativa metáfora del carácter mediador entre la situación propia del Bronce y la que a continuación introduce el Hierro II. Este emplazamiento introduce la última novedad significativa a la que me voy a referir: frente a unos poblados vueltos sobre sí mismos y su entorno más inmediato en la Edad del Bronce (Méndez, 1994, 1998), los primeros castros introducen la visibilidad a larga distancia como un factor esencial en la selección del emplazamiento. Y lo hacen concentrando esta visibilidad precisamente en la dirección opuesta a aquella que, por lo que parece, acogería su espacio prioritario de explotación. Así, estos primero castros muestran un muy amplio dominio

(16) Agradezco el dato a mi compañero Manuel Santos.

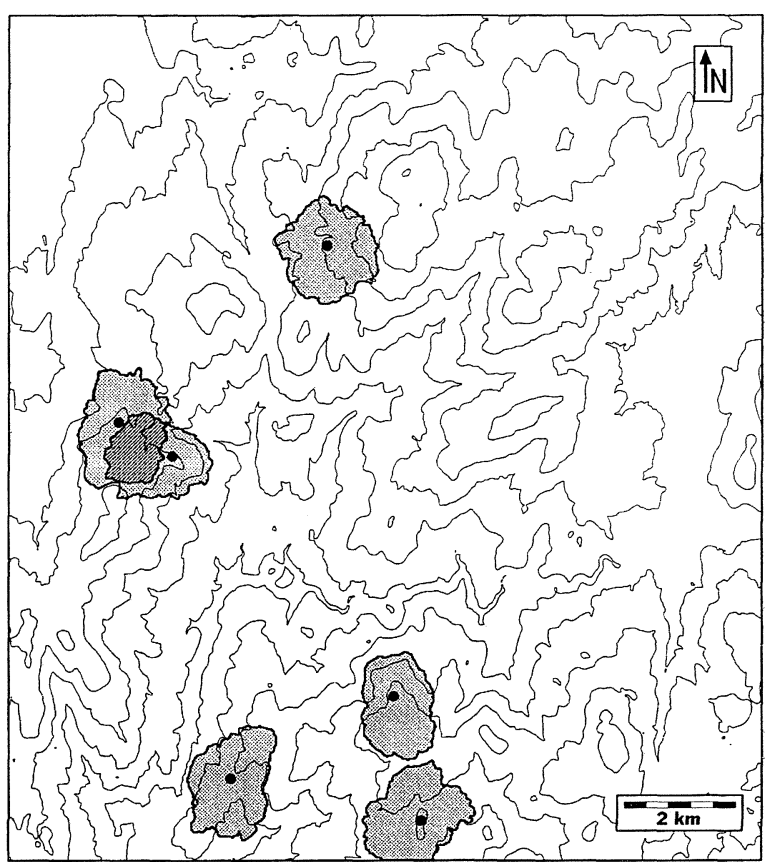

Fig. 9. Isocrona de 30 minutos a partir de los castros de probable adscripción al Hierro I.

visual de los valles, lo que refrenda de nuevo la metáfora anterior: se empieza a mirar (literalmente) al valle, aunque todavía a distancia.

\subsubsection{La ocupación en el Hierro II}

Los yacimientos que he asignado a la segunda Edad del Hierro reflejan una modificación en las formas de entender la vinculación entre las comunidades humanas y la naturaleza y, por extensión, la manera en que estas comunidades se organizan y estructuran. Ahora los yacimientos aparecen inmersos en entornos menos dominantes, en puntos en general más bajos, en contacto directo con el valle. Parece que la progresiva aproximación de los grupos humanos a las tierras bajas alcanza ahora un hito importante. Los yacimientos están rodeados de terrenos fértiles, bien irrigados y lo suficientemente profundos como para permitir sistemas de explotación más intensivos, con ciclos de rotación cortos. Esta posibilidad requiere, a cambio, disponer de una tecnología más avanzada, capaz de remover y airear los suelos en el momento de la labra y de abordar obras de drenaje ante los riesgos de encharcamiento de estas superficies de recepción de aguas y escasa pendiente.

A este respecto puede resultar bastante signifi- 
cativo constatar que es precisamente a partir de los siglos V-IV a.C. cuando se generaliza la metalurgia del hierro en el noroeste, dado que los escasos útiles de este metal documentados en contextos anteriores parecen proceder mayoritariamente de la importación y tener un uso efectivo limitado (Peña, 1992b). Es igualmente ilustrativo constatar que a partir de este momento hacen su aparición en los castros voluminosos espacios de almacenamiento de excedente (Fernández-Posse y Sánchez Palencia, 1998). En otros órdenes de la cultura material, como la cerámica, parece documentarse igualmente un cambio significativo que afecta no sólo a la apariencia o los tipos de los materiales ahora fabricados sino a la concepción global de la cultura material (Rey, 1990-91; Cobas y Prieto, 1998; Cobas, 1999).

Los yacimientos muestran a un tiempo evidencias de continuidad y discontinuidad. Ya se ha analizado cómo varían sus patrones de localización y cómo se altera de forma notable la vinculación con el entorno. Los castros de este momento parecen mostrar una clara vocación de integración con los terrenos circundantes, manifestada en unas condiciones de accesibilidad y de un dominio visual uniformes en todas direcciones. La alta preocupación por la inaccesibilidad que trasmiten los asentamientos del Hierro I decrece en este momento. Los nuevos poblados siguen ocupando puntos estratégicos, dominantes sobre el entorno más inmediato y relativamente difíciles de alcanzar. Sin embargo pesa más la necesidad de disponer cómodamente de superficies suficientes de terrenos aptos para la explotación intensiva, entendida como un sistema de barbecho de ciclo corto.

A cambio la protección del espacio doméstico, de las vidas y las posesiones de los miembros de la comunidad, reposa mucho más sobre el propio trabajo de éstos. Son ahora las estructuras defensivas artificiales las que construyen nuevas formas de relieve, las que funcionan de forma primordial como delimitadores del espacio directamente ocupado, tanto para su habitación como, muy probablemente, para su explotación más directa e intensiva. Es así como podrían leerse las numerosas terrazas que aparecen rodeando muchos castros y que, al menos en algún caso con certeza, se pueden vincular con ocupaciones de este momento (Parcero, 1999a) (17).

(17) Datos derivados del reciente proyecto de control arqueológico de la construcción de la Red de Gasificación de Galicia.
Además de elementos defensivos y delimitadores de los poblados, las estructuras artificiales que ahora se generalizan, sobre todo parapetos y murallas, introducen una nueva modificación respecto al momento anterior. Frente a aquel carácter visualmente abierto de los poblados del Hierro I, los nuevos castros aparecen rodeados, casi siempre íntegramente, por un horizonte artificial constituido por sus propias defensas. Se consigue así una sensación de espacio cerrado, volcado sobre sí mismo, ya que se impide (por completo en algunos casos, parcialmente en otros) la visión al exterior desde cualquier punto de la aldea a no ser que nos encaramemos a la parte alta de las defensas.

Se asiste, en fin, a un nuevo modelo de paisaje que, sin embargo, mantiene al menos un elemento de continuidad estructural con la fase anterior. $\mathrm{Me}$ refiero a la perduración del poblamiento en pequeñas aldeas fortificadas. Este solo rasgo, incluso en ausencia de otros, es, a mi juicio, lo suficientemente importante como para hacerlo prioritario frente a las rupturas a la hora de etiquetar cada uno de estos períodos.

\subsubsection{El dilema de la tercera fase}

Se apuntó más arriba que en general se reconoce la existencia de tres fases dentro de la secuencia del mundo castreño del noroeste. De hecho existe un acontecimiento histórico innegable que afectó a este área: la ocupación y dominio romano. Sin embargo el análisis que he realizado sólo permite distinguir dos modelos de ocupación en la zona de trabajo. ¿Qué ocurre, pues, con esta última fase? Estamos ante el complejo dilema del efecto de la ocupación romana en el noroeste.

El tema es lo suficientemente rico como para justificar un trabajo detenido y exhaustivo, que aquí no corresponde. Me limitaré a apuntar algunas precisiones. Como ya se señaló, en la zona concreta que he seleccionado no parece detectarse ninguna modificación sustancial del patrón de ocupación del medio aparte de ese esquema dual Hierro I/Hierro II. Estos datos pueden ser mejor valorados si echamos mano de la información directa que nos ofrecen yacimientos que hayan sido excavados. En la tabla I se han recogido una serie de castros del área gallega con información contextualizada y publicada con un mínimo detalle. Como se puede observar, la gran mayoría de los ocupados en los momentos más tardíos de la cultura castreña, esto es, en épo-

T. P., 57, n. ${ }^{\circ} 1,2000$ 


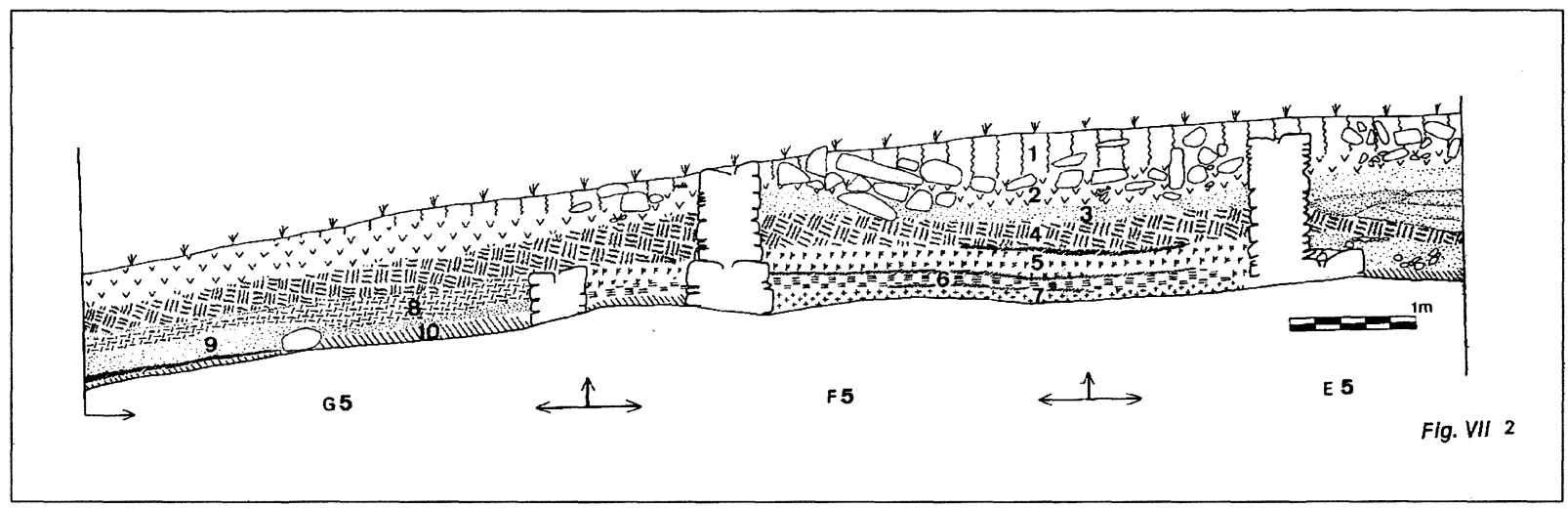

Fig. 10. Perfil del castro de Baroña en el que se aprecia la exacta superposición de estructuras en dos fases de ocupación sucesivas (Calo y Soeiro, 1986).

ca indígeno-romana ( $c a$. a partir del siglo I a.C.), cuentan con ocupaciones anteriores, en algunos casos bien contrastadas y en otros apuntadas por algunos indicios que obligan al menos a tomar cierta cautela (18).

Esta aparente continuidad se ve refrendada por la forma en que se producen en muchos casos estas reocupaciones. Así, en los bien conocidos castros de Troña o Baroña los excavadores aluden reiteradamente a la frecuente reutilización de las mismas estructuras domésticas en fases sucesivas de lo que sería el Hierro II y época indígeno-romana (19) (Hidalgo, 1988-89; Calo y Soeiro, 1986). Véase un buen ejemplo de ello en el perfil de la figura 10 correspondiente al castro de Baroña. El yacimiento de Alto do Castro, al que luego me referiré, apunta en la misma dirección (Parcero, e.p.).

De estas observaciones se puede extraer, al menos de forma preliminar, que la ocupación y dominio romano en el noroeste no siempre implicó una modificación importante en los modelos de ocupación y construcción del paisaje. Es conocido e in-

(18) Así ocurre en A Croa de Ladrido, castro con muy escasa superficie excavada. En Santa Tecla sí se ha excavado una superficie muy amplia, pero los trabajos (al menos los más recientes, que son los únicos con información fiable) se han concentrado en un único sector de un yacimiento de gran extensión y que podría haber seguido un proceso conocido: mutación del tamaño del poblado pero mantenimiento del modelo de ocupación, que es lo que ahora mismo se está examinando. El caso de Viladonga es más oscuro por falta de información publicada suficientemente explícita, aunque parecen existir materiales de clara adscripción prerromana (Dorrego y Rubiero, 1998).

(19) Los excavadores del castro de Baroña identifican hasta 4 fases de ocupación, que reducen a un lapso de apenas 100 años entre los siglos I a.C. y II d.C. Sin embargo tanto el examen de los motivos que les llevan a esta conclusión como el análisis detenido del material cerámico (Rey, 1990-91) permiten retrasar la cronología de sus primeras ocupaciones hasta el Hierro II. No se conocen dataciones de C-14 para el yacimiento. negable que donde la ocupación romana tuvo especial intensidad por razones esencialmente económicas, sí ocurrió (Fernández-Posse y Sánchez Palencia, 1998). Sin embargo no parece que esto haya ocurrido fuera de estas áreas. Es igualmente cierto que hay castros fundados en esta época alejados de las zonas de intensidad minera prioritaria, pero, al nivel de análisis actual, esos yacimientos no habrían roto el modelo de localización, ocupación y relación con el medio de las comunidades prerromanas; en una palabra, el modelo de paisaje.

¿Significa esto la negación de cualquier relevancia o efecto de la conquista y dominio romano del noroeste? En absoluto. Únicamente significa que, en primer lugar, estos efectos se van a producir a un nivel diferente del paso de la primera a la segunda Edad del Hierro. No aparece un nuevo modelo de paisaje, ni una concepción diferente de la relación entre las comunidades y el medio, de ocupación y explotación del entorno. Lo que sí hay es, sobre todo, la inclusión de una sociedad formada por comunidades campesinas con un modesto grado de integración política dentro de la estructura de dominación de un imperio.Y ello sin duda habrá ocasionado modificaciones relevantes dentro de estas comunidades, pero estas modificaciones, como se ha apuntado recientemente (Sastre, 1998), parecen ir más en la línea del aprovechamiento de las estructuras socio-políticas y de poder precedentes, reajustando los equilibrios existentes, reforzando las bases del poder en unos casos o eliminándolas en otros. La constitución del campesinado corresponde a los grupos prerromanos; lo que ahora se produce es su inclusión en una vasta estructura imperial. La destrucción definitiva del equilibrio existente no se registra hasta el momento en que los castros se aban- 


\begin{tabular}{|c|c|c|c|c|}
\hline Yacimiento & Hierro I & Hierro II & $\begin{array}{l}\text { Indígeno- } \\
\text { romano }\end{array}$ & Referencias \\
\hline Coto dos Mouros (Moraña, Pontevedra) & \& & & & Álvarez, 1986, 1987 \\
\hline O Neixón Pequeno (Boiro, A Coruña) & 4 & & & Acuña,1976; Fariña y Arias, 1980 \\
\hline O Tallo (Ortigueira, A Coruña) & क\% & & & Ramil,1989 \\
\hline Penalba (Campolameiro, Pontevedra) & +4 & & & $\begin{array}{l}\text { Alvarez,1986, 1987; Carballo y } \\
\text { Fábregas,1991 }\end{array}$ \\
\hline Penarrubia (Lugo) & +4 & & & $\begin{array}{l}\text { Arias,1979; Carballo y Fábregas, } \\
1991\end{array}$ \\
\hline Torroso (Mos, Pontevedra) & at & & & Peña,1992a \\
\hline A Graña (Toques, A Coruña) & के & +4 & क* & Meijide, 1990 \\
\hline Alto do Castro (Cuntis, Pontevedra) & क* क & tot & +4 & Parcero, $1999 \mathrm{~b}$ \\
\hline Castrovite (A Estrada, Pontevedra) & 4\% & +4 & $4 \%$ & Carballo, 1998 \\
\hline Troña (Ponteareas, Pontevedra) & कt & tot & +4 & $\begin{array}{l}\text { Hidalgo, 1988-9; Carballo y } \\
\text { Fábregas, } 1991\end{array}$ \\
\hline Castromao (Celanova, Ourense) & 4t & tot & ato & $\begin{array}{l}\text { Fariña,1991; Carballo y Fábregas, } \\
\text { 1991; Rey, 1990-1 }\end{array}$ \\
\hline Toralla (Vigo, Pontevedra) & 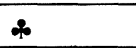 & +4 & $\leftrightarrow 4$ & Hidalgo, 1990-1 \\
\hline Baroña (Porto do Son, A Coruña) & $\div$ & t+ & +4 & Calo y Soeiro,1986; Rey, 1990-1 \\
\hline Borneiro (Cabana, A Coruña) & & at & क* & $\begin{array}{l}\text { Romero, 1987; Carballo y Fábregas, } \\
1991\end{array}$ \\
\hline Coto do Mosteiro (O Carballiño, Ourense) & & +4 & +4 & Orero, 1988 \\
\hline Cameixa (Boborás, Ourense) & & tot & +4 & $\begin{array}{l}\text { López y Lorenzo,1986; Carballo y } \\
\text { Fábregas, 1991; Rey, 1990-1 }\end{array}$ \\
\hline Fozara (Ponteareas, Pontevedra) & & at & at & $\begin{array}{l}\text { Hidalgo y Rodríguez,1987; } \\
\text { Carballo y Fábregas, } 1991\end{array}$ \\
\hline Vigo (Vigo, Pontevedra) & & 4क & 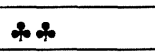 & Hidalgo, 1985 \\
\hline Santa Tecla (A Guarda, Pontevedra) & & 4 & 4 & Peña,1985-6; Carballo,1989 \\
\hline Viladonga (Castro de Rei, Lugo) & & * & क4 & $\begin{array}{l}\text { Arias y Durán, 1996; Dorrego y } \\
\text { Rubiero, } 1998\end{array}$ \\
\hline A Croa de Ladrido (Ortigueira, A Coruña) & & 4 & $\$$ & Ramil,1989 \\
\hline A Forca (A Guarda, Pontevedra) & & tक & & Carballo, 1987 \\
\hline Cartimil (Silleda, Pontevedra) & & & क4 & $\begin{array}{l}\text { Carballo y Fábregas, } 1991 ; \\
\text { Carballo, } 1990\end{array}$ \\
\hline Punta dos Prados (Espasante, A Coruña) & & & $\%$ & Ramil,1995/6 \\
\hline O Marco (Silleda, Pontevedra) & & & क4 & $\begin{array}{l}\text { Carballo y Fábregas, } 1991 ; \\
\text { Carballo,1990 }\end{array}$ \\
\hline San Cibrán de Lás (San Amaro, Ourense) & & & \& * & Rodríguez, Xusto y Fariña,1993 \\
\hline
\end{tabular}

Tab. I. Clave: Ocupación segura Indicios.

donan y se adopta una nueva forma de comunidades, de paisaje, en la que seguramente ya se puede hablar de la existencia de clases sociales nítidas en función de un acceso diferencial a los medios de producción. Pero esto es otra historia.

\subsubsection{Otras opciones: abandono frente a reocupación}

Hasta aquí he presentado la lectura de los dos modelos de localización de castros detectados en la zona. Pero, como es bien conocido, la situación dista habitualmente de ser tan clara. En efecto, como se aprecia en la tabla I, un alto porcentaje de los castros está lejos de adaptarse canónicamente a este esquema de dos situaciones sucesivas, a uno $\mathrm{u}$ otro modelo de forma excluyente. Es relativamente frecuente que hayan sido reutilizados no sólo a partir del siglo IV a.C. sino también desde épocas anteriores, solapándose ocupaciones de lo que he denominado Hierro I y II. ¿Invalida esto la verosimilitud del esquema presentado? Un examen detenido de la forma en que se producen estas re-

T. P., 57, n. ${ }^{\circ} 1,2000$ 


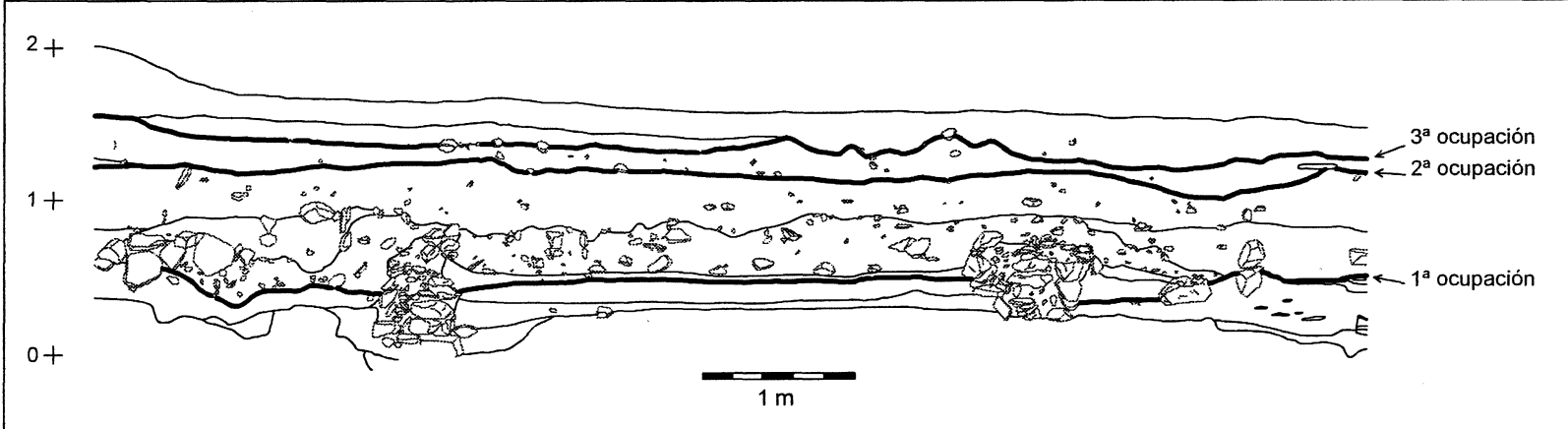

Fig. 11. Perfil del yacimiento de Alto do Castro en el que se señalan con trazo más grueso las superficies de las tres fases de ocupación (Parcero, e.p.).

currencias servirá para matizar esta aparente incoherencia.

Para este análisis me voy a basar en el yacimiento de Alto do Castro por dos motivos esenciales. El primero es que muestra muy nítidamente una larga pervivencia que abarca los dos momentos considerados, así como una ulterior fase de época indígeno-romana. El segundo es que lo conozco especialmente bien por haber participado en el trabajo arqueológico en él desarrollado (20).

Este pequeño castro, situado a menos de $10 \mathrm{~km}$ al norte de la zona que ahora nos ocupa, cuenta con tres fases de ocupación bien caracterizadas (corroboradas por dataciones de C-14): la primera fase se desarrolla con anterioridad al sigloV a.C., la segunda entre los siglos IV-II a.C. y la última entre este momento y, aproximadamente, el cambio de era. Podría pensarse, pues, que hay una clara continuidad en todo este lapso. Y es cierto. Pero sólo al nivel al que antes fue expuesta: pervivencia en una forma de poblado, la aldea fortificada, y, en este caso, permanencia además en el mismo lugar. Esta pervivencia es, como también se apuntó antes, crucial, estructural y, seguramente, más significativa que la discontinuidad. Pero también ésta existe. Se manifiesta sobre todo en que el paso entre la primera y segunda fases ( $c a$. siglo V a.C.) significa no sólo un abandono temporal del poblado, como la que ocurre entre las dos fases recientes, sino una profunda reforma del mismo, hasta el punto que podría hablarse de una refundación. La estratigrafía vertical lo muestra nítidamente (Fig. 11): la to-

(20) Fidel Méndez dirigió su excavación en 1993. La mayor parte de los datos que siguen permanecen inéditos. Existe una noticia acerca de esta excavación (Méndez et alii, 1995) y en este mismo año se publicará una síntesis (Parcero, e.p.), extraída de la memoria definitiva. talidad de niveles y estructuras de la primera fase son no sólo olvidados sino sepultados bajo espesas capas de tierra que incluyen el propio derrumbe de esas estructuras y la deposición de importantes niveles de sellado y preparación del terreno. La reforma de las defensas al norte del poblado es igual de brusca (Fig. 12): frente a un ligero refuerzo y adición de un murete de contención en la fase final, en la fase intermedia se erige prácticamente un nuevo parapeto sobre el anterior que duplica su altitud y anchura, además de añadirse un nuevo foso de igual proporción. El alcance de la reforma se puede adivinar también en la propia extensión del poblado, ya que ahora aumenta considerablemente su superficie (dentro de unas dimensiones en general reducidas) y varía su apariencia y planta.

Es ésta, pues, una manifestación alternativa del proceso de modificación que se vive entre el Hierro

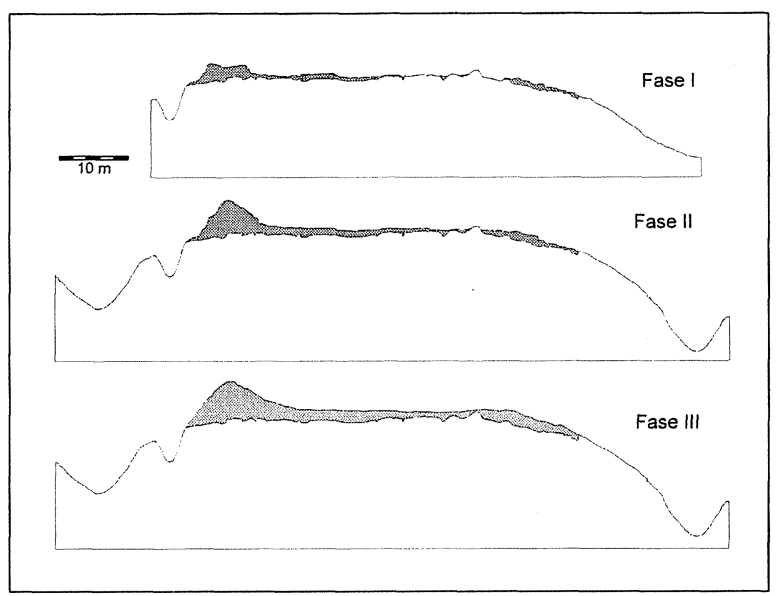

Fig. 12. Secuencia esquemática de la amplitud y entidad estratigráfica de las tres fases de ocupación deAlto do Castro (simplificación del perfil completo del yacimiento, Parcero, e.p.). 
I y el II. El yacimiento no se abandona pero tampoco se reocupa de forma estricta, sino que más bien se reconstruye. Podemos hablar con más propiedad de una recurrencia en la ocupación que de una nueva utilización del poblado. Este modelo parece repetirse, por ejemplo, en Castrovite (A Estrada, Pontevedra) (Carballo, 1998), aunque la información disponible no permite precisar demasiado.

Resta aún justificar por qué en algunos casos se registra el abandono definitivo de un poblado y en otros se opta por la continuidad. En el estado actual creo poder aludir a dos motivos. El primero es lo que se puede denominar la posibilidad: la localización del poblado continúa siendo válida para el nuevo contexto de explotación del medio. En efecto Alto do Castro muestra muchos de los rasgos que definen el modelo de localización de los castros del Hierro I, aunque su posición es tal que no implica un distanciamiento exagerado de los terrenos de potencial aprovechamiento intensivo. Así, estaríamos aquí ante un ejemplo de patrón de localización intermedio, tan apto para la explotación de suelos ligeros como de terrenos de valle. Una buena prueba de este extremo es que la pervivencia de la ocupación en el lugar de Alto do Castro no sólo afecta al amplio ciclo de la Edad del Hierro, sino que a sus pies hay evidencias de un asentamiento tardorromano y, más adelante, se situó la actual aldea de Laxos (Parcero, e.p.).

El segundo motivo sería la necesidad: el potencial de la propia comunidad que lo habita. Alto do Castro es, como se ha dicho, muy pequeño, incluso dentro de los parámetros de un castro del Hierro I. Ello implica una comunidad de muy modestas dimensiones, tal vez no más de 60 ó 70 individuos. Un grupo como éste enfrentado al dilema de levantar un nuevo poblado de la nada o reformar el ya existente (por profunda que sea esta reforma) seguramente habrá escogido la primera alternativa. Esta opción de continuidad y pervivencia parece la preferente en zonas con peores condiciones para una ocupación intensiva y en las que el rigor del medio proporciona un menor margen de maniobra a las comunidades (21).

(21) Tal es el caso del área de Friol (Lugo), que ahora estoy analizando con el mismo esquema de trabajo y que muestra un conjunto de yacimientos mucho más homogéneo. Inmediatamente vecina a ésta está la sierra de O Bocelo, donde se excavaron o sondearon varios castros que parecen confirmar esa mayoritaria opción de pervivencia en la ocupación de un mismo punto durante largo tiempo (Penedo y Rodríguez Puentes, 1991; Meijide, 1990).

T. P., 57, n. $^{\circ} 1,2000$

\section{SÍNTESIS: LAS DOS EDADES DEL HIERRO}

Tres fases, dos modelos. Esta frase podría sintetizar una parte de los resultados del trabajo. Cuando menos en la zona que aquí se ha empleado como ejemplo, resultan en principio evidentes dos modos únicos de ocupación del espacio nítidamente diferenciados durante el largo período de vigencia del poblamiento castreño fortificado. Esos dos modelos se corresponden con lo que dentro del peculiar contexto investigador norteño se denominan Fase I o inicial del mundo castreño y Fases II y III, o media y final, de ese "complejo cultural". Hablando en términos más generales, se puede correlacionar sin ningún problema el registro del noroeste con el del resto de la Península Ibérica y Europa y hablar de Hierro I y Hierro II-época indígeno-romana.

Como también se ha mostrado, esta secuencia tripartita contiene a su vez una base en apariencia sólida, ya que se detectan cambios también significativos derivados de la ocupación romana. ¿Cómo congeniar, pues, esta aparente dualidad? La respuesta parece que se debe situar en una valoración ajustada del diferente carácter de estos dos procesos de cambio y de su alcance.

El paso de la primera a la segunda Edad del Hierro, hacia finales del siglo V a.C., es un cambio sustantivo y estructural en los modos de vida y organización socio-política de las comunidades castreñas. La clara modificación en los patrones formales y de emplazamiento de los yacimientos es nada más que un reflejo de una alteración importante en las formas de ocupar y explotar el medio, que a su vez habría implicado un cambio en los modos de conceptualizarlo. La esencia de ese cambio sería la plena conformación del campesinado, en la forma en que éste se ha definido en otros lugares para el mundo castreño (Parcero, 1995; Fernández-Posse y Sánchez Palencia, 1998).

El segundo cambio es de naturaleza diferente. En primer lugar porque en él juega un papel esencial un elemento externo y bien distinto: el imperialismo romano, bien sea como inductor principal o mero impulsor. En segundo lugar porque los efectos de este cambio parecen obrar a otro nivel. En principio no parece haber una alteración en las bases de la estructura socio-política de las comunidades castreñas, sino más bien una exacerbación de las formas organizativas ya existentes. Un claro síntoma de ello es el aparente mantenimiento de las formas de ocupación y relación de las comunidades con el espacio. 
Ahora bien, todo esquema general (y éste lo es) es siempre un modelo, una abstracción, pero las posibilidades de adaptación local son muchas. Así ocurriría a nivel regional, donde por ejemplo parece haber áreas en las que predominan las ocupaciones de muy largo alcance y los cambios entre la primera y segunda Edad del Hierro habrían operado a escala local, dentro de cada yacimiento. Alto do Castro podría marcar una pauta de lo que ocurre en áreas de poblamiento poco denso y de mayor rigor para la ocupación como Friol, en el interior de Galicia. A nivel igualmente regional hay lugares en los que la ocupación romana sí supuso una mutación significativa de las formas de poblamiento, con presencia permanente e interés directo del estado romano como el área minera de León, Asturias y oriente gallego. También pueden existir adaptaciones locales, dentro de cada comunidad concreta, dentro de cada poblado. Así ocurriría en Alto do Castro, próximo a la zona de estudio principal pero donde el cambio entre Hierro I y II no se produce por medio del abandono del poblado sino manteniendo el lugar de habitación.

\section{AGRADECIMIENTOS}

Gracias a Fidel Méndez, por compartir muchas ideas y también padecimientos para entendernos con las máquinas, cosa que por supuesto no hemos conseguido.A Manuel Santos, por tener siempre un momento para pensar. Como cualquiera que me conozca puede saber, los números nunca han sido lo mío; por ello buena parte de los análisis requirieron de la ayuda de mis compañeros César A. González y Roberto Gómez. Gracias evidentes a Felipe Criado, por apretar pero no ahogar. Y gracias a los que revisaron y mejoraron el texto, a saber: Isabel Cobas y Xurxo Ayán.

\section{BIBLIOGRAFÍA}

Acuña Castroviejo, F. (1976): "Excavaciones en el castro de 'O Neixón'. Campaña de 1973”. NoticiarioArqueológico Hispánico, Prehistoria, 5: 325-330.

AlarÇão, J. DE (1992): "A evolução da Cultura Castreja". Conimbriga, XXXI: 39-71.

Álvarez NúÑez, A. (1986): Castro de Penalba. Campaña 1983. Col. Arqueoloxía/Memorias, 4. Xunta de Galicia. Santiago de Compostela.

- (1987): "Castro de Penalba (Campolameiro) y Castro dos Mouros (Moraña). Campaña de excavaciones 1987".El Museo de Pontevedra, 41: 97-111.
ArIas VILAS, F. (1979): "El castro de Penarrubia (Lugo) y la novedad de su datación por C-14". Actas del XV Congreso Nacional de Arqueología (Lugo, 1977): 613622. Zaragoza.

Arias Vilas, F. y Durán Fuentes, M.C. (1996): Museu do Castro de Viladonga (Castro de Rei, Lugo). Xunta de Galicia. Santiago de Compostela.

Calo Lourido, F. y Soeiro, T. (1986): Castro de Baroña. Campañas 1980-84. Col. Arqueoloxía/Memorias, 6. Xunta de Galicia. Santiago de Compostela.

Carballo Arceo, L.X. (1987): Castro da Forca. Campaña 1984. Col. Arqueoloxía/Memorias, 8. Xunta de Galicia. Santiago de Compostela.

- (1989): Catálogo dos materiais arqueolóxicos do museu do castro de Santa Trega: Idade do Ferro. Excma. Diputación Provincial de Pontevedra. Pontevedra.

- (1990): "Los castros de la cuenca media del río Ulla y sus relaciones con el medio físico". Trabajos de Prehistoria, 47: 161-199.

- (1996): “Os castros galegos: espacio e arquitectura". Gallaecia, 14-15: 309-58.

- (1998): "Agricultura en Castrovite (Orazo, A Estrada) durante a Idade do Ferro". A Estrada, 1: 9-25.

Carballo Arceo, L.X. y Fábregas Valcarce, R. (1991): "Dataciones de C-14 para castros del noroeste peninsular". Archivo Español de Arqueología, 64, 163-164: 244-264.

CARDESín DíAz, J.M. (1992): Tierra, trabajo y reproducción social en una aldea gallega (s. XVIII-XX): Muerte de unos, vida de otros. Ministerio de Agricultura, Pesca y Alimentación. Madrid.

CoBAS FernándeZ, I. (e.p.): "Introducción a la cerámica de la Prehistoria de Galicia II: La cerámica de la Edad del Hierro del NW Peninsular". En I. Cobas Fernández y P. Prieto Martínez: Introducción a la cerámica Prehistórica y Protohistórica de Galicia. Col. Trabajos en Arqueología del Paisaje, 17. Grupo de Investigación en Arqueología del Paisaje. Santiago de Compostela. (2000)

Cobas Fernández, I. y Prieto Martínez, P. (1998): “Regularidades espaciales en la cultura material: la cerámica de la Edad del Bronce y la Edad del Hierro en Galicia." Gallaecia, 17: 151-75.

Criado BoAdo, F. (1993a): "Visibilidad e interpretación del registro arqueológico". Trabajos de Prehistoria, 50: 39-65.

- (1993b): "Límites y posibilidades de la Arqueología del Paisaje". Spal, 2: 9-55.

Díaz-Fierros Viqueira, F. y Gil Sotres, F. (1984): Capacidad Productiva de los suelos de Galicia. Universidade de Santiago. Santiago de Compostela.

Dorrego Martínez, F. y Rubiero da Pena, A.M. (1998): "Consideracións sobre os temas decorativos na cerámica castrexa de Viladonga". Croa, 8: 21-28.

EsCRIBANo Bombín, M.M. (dir.) (1991): El paisaje. MOPU. Madrid. 
Fariña Busto, F. (1991): "Dos notas a propósito de Castromao". Cuadernos de Estudios Gallegos, XXXIX, 104: 57-71.

Fariña Busto, F. y Arias Vilas, F. (1980): “Aportazón ao estudo das Fíbulas atopadas nos Castros Galegos". Actas del Seminario de Arqueología del Norte Peninsular (Guimarâes, 1979), II: 183-195. Guimarâes.

Fariña Busto, F.; Arias Vilas, F. y Romero Masiá, A. (1983): "Panorámica general sobre la cultura castreña". En G. Pereira Menaut (ed.): Estudos de Cultura Castrexa e de Historia Antiga de Galicia. Universidade de Santiago. Santiago de Compostela: 87-127.

FERNÁNDEZ-Posse, M.D. (1998): La investigación protohistórica en la Meseta y Galicia. Síntesis. Madrid.

Fernández-Posse, M.D. y SÁnchez Palencia, F.J. (1998): "Las comunidades campesinas en la cultura castreña". Trabajos de Prehistoria, 55(2): 127-150.

Hidalgo Cuñarro, J.M. (1985): Castro de Vigo. Campaña 1983. Col. Arqueoloxía/Memorias, 1. Xunta de Galicia. Santiago de Compostela.

- (1988-89): "Excavaciones arqueológicas en Troña (Ponteareas, Pontevedra). Campañas 1984-86". Castrelos, 1-2: 81-108.

- (1990-91): "Últimas excavaciones de urgencia en Vigo: castros y yacimientos romanos". Castrelos, 3-4: 191215.

Hidalgo Cuñarro, J.M. y Rodríguez Puentes, E. (1987): Castro de Fozara. Campaña 1984. Col. Arqueoloxía/ Memorias, 9. Xunta de Galicia. Santiago de Compostela.

LEUSEN, M. VAN (1999): "Viewshed and Cost Surface Analisys using GIS (Cartographic Modelling in a CellBased GIS II". En J.A. Barceló, I. Briz y A. Vila (eds.): New Techniques for Old Times. CAA 98 - Computer Applications and Quantitative Methods in Archaeology. Proceedings of the 26th Conference (Barcelona, 1998). British Archaeological Reports, Int. Series, S757. Oxford: 215-223.

López Cuevillas, F. y Lorenzo Fernández, X. (1986): Castro de Cameixa. Campañas 1944-46. Col.Arqueoloxía/Memorias, 0. Xunta de Galicia. Santiago de Compostela.

Martins, M. (1988). "A arqueología dos castros no Norte de Portugal: balanço e perspectivas de investigaçâo". Trabalhos de Antropologia e Etnologia, 28, 3-4: 11-35.

Meijide Cameselle, G. (1990): "Tres dataciones de C-14 del castro de A Graña (Toques, A Coruña) y su contexto arqueológico". Gallaecia, 12: 111-134.

MÉndez FernÁndeZ, F. (1994). "La domesticación del paisaje durante la Edad del Bronce gallego". Trabajos de Prehistoria, 51(1): 77-94.

- (1998). "Definición y análisis de poblados de la Edad del Bronce en Galicia". En R. Fábregas Valcárce (ed.): A Idade do Bronce en Galicia: novas perspectivas. Col. Cadernos do Seminario de Sargadelos, 77. Ediciós do Castro. Sada: 153-90.
Méndez Fernández, F.; Parcero Oubiña, C. y CRiado BoADO, F. (1995): "Problemática de la Excavación en el Marco del Seguimiento Arqueológico de una Obra de Trazado Lineal". Actas del XXII Congreso Nacional de Arqueología (Vigo, 1993), I: 317-22. Vigo.

Orero Grandal, L. (1988): Castro Coto do Mosteiro. Campañas 1984-85. Col.Arqueoloxía/Memorias, 10. Xunta de Galicia. Santiago de Compostela.

Parcero Oubiña, C. (1995): "Elementos para el estudio de los paisajes castreños del Noroeste Peninsular". Trabajos de Prehistoria, 52(1): 127-44.

- (1999): La arqueología en la gasificación de Galicia, 7. Hacia una arqueología agraria de la cultura castreña. Col. Trabajos en Arqueología del Paisaje, 9. Grupo de Investigación en Arqueología del Paisaje. Santiago de Compostela.

- (e.p.): "Síntesis de los trabajos de excavación en el yacimiento castreño de Alto do Castro (Cuntis, Pontevedra)". Brigantium, 12 (1999).

Parcero Oubiña, C.; Criado Boado, F. y Santos Estévez, M (1998): "Rewriting Landscape: Incorporating Sacred Landscapes into Cultural Traditions". World Archaeology, 30(1): 159-76

Penedo Romero, R. y Rodríguez Puentes, E. (1991): "La Edad del Hierro. Formas concretas del paisaje fortificado" En F. Criado (dir.): Arqueología del Paisaje. El área Bocelo-Furelos entre los tiempos paleolíticos y medievales. Col. Arqueoloxía/Investigación, 6. Xunta de Galicia. Santiago: 199-220.

Peña Santos, A. DE LA (1985-86): “Tres años de excavaciones arqueológicas en el yacimiento galaico-romano de Sta. Tecla (A Guarda, Pontevedra): 1983-85". Pontevedra Arqueológica, II: 157-189.

- (1992a): Castro de Torroso. Síntesis de las memorias de las campañas de excavación 1984-1990. Col.Arqueoloxía/Memorias, 11. Xunta de Galicia. Santiago de Compostela.

- (1992b). "El primer milenio a.C. en el área gallega: Génesis y desarrollo del mundo castreño a la luz de la arqueología". En M.Almagro Gorbea y G. Ruiz Zapatero (eds.): Paleoetnología de la Península Ibérica.Actas del Coloquio sobre Etnogénesis de la Península Ibérica (Madrid, 1989). Complutum Extra, 2-3: 373-94.

Peña Santos, A. de la y Vázquez Varela, J.M (1996): "Aspectos de la génesis y evolución de la cultura Castreña de Galicia”. En M.A. Querol y T. Chapa (eds.): Homenaje al Prof. Manuel Fernández-Miranda. Complutum Extra, 6-I: 255-263.

RAmil GonZÁlEZ, E. (1989): "Castros do concello de Ortigueira (Ortigueira, A Coruña)".Arqueoloxía/Informes, 1: 58-63.

- (1995-96): "O monumento con forno do castro dos Prados (Espasante). Memoria de investigación". Brigantium, 9: 13-60.

Rey CAstiñeiRA, J. (1990-91): "Cerámica indígena de los castros costeros de la Galicia occidental: Rías Bajas.

T. P., 57, n. $^{\circ} 1,2000$ 
Valoración dentro del contexto general de la Cultura Castreña". Castrelos, 3-4: 141-163.

Rodríguez CaO, C.; Xusto Rodriguez, M. y Fariña Busto, F. (1993): A Cidade de San Cibrán de Lás. Col. Guías do Patrimonio Cultural, 4. Grupo Marcelo Macías de colaboradores do Museo Arqueológico. Ourense.

Romero Masiá, A. (1987): Castro de Borneiro. Campañas 1983-84. Col. Arqueoloxía/Memorias, 7. Xunta de Galicia. Santiago de Compostela.

SAntos Estévez, M. (1998): "Los espacios del arte: el diseño del panel y la articulación del paisaje en el arte rupestre gallego". Trabajos de Prehistoria, 55(2): 73-88.

Santos Estévez, M.; Parcero Oubiña, C. y Criado Boado,
F. (1997): "De la arqueología simbólica del paisaje a la arqueología de los paisajes sagrados". Trabajos de Prehistoria, 54(2): 61-80.

SAstre Prats, I. (1998): Formas de dependencia social en el noroeste peninsular. Transición del mundo prerromano al romano y época altoimperial. Instituto de Estudios Bercianos. Ponferrada.

Silva, A. C. Ferreira dA (1986): A cultura castreja no Noroeste de Portugal. Museu Arqueológico da Citânia de Sanfins. Paços de Ferreira.

Xusto Rodríguez, M. (1992): "La concepción territorial en la cultura castreña de Galicia”. Revista de Arqueología, 137: 28-37. 